\title{
Learning About Ares I from Monte Carlo Simulation
}

\author{
John M. Hanson ${ }^{1}$ and Charles E. Hall ${ }^{2}$ \\ NASA Marshall Space Flight Center, Huntsville, AL 35812
}

This paper addresses Monte Carlo simulation analyses that are being conducted to understand the behavior of the Ares I launch vehicle, and to assist with its design. After describing the simulation and modeling of Ares I, the paper addresses the process used to determine what simulations are necessary, and the parameters that are varied in order to understand how the Ares I vehicle will behave in flight. Outputs of these simulations furnish a significant group of design customers with data needed for the development of Ares I and of the Orion spacecraft that will ride atop Ares I. After listing the customers, examples of many of the outputs are described. Products discussed in this paper include those that support structural loads analysis, aerothermal analysis, flight control design, failure/abort analysis, determination of flight performance reserve, examination of orbit insertion accuracy, determination of the Upper Stage impact footprint, analysis of stage separation, analysis of launch probability, analysis of first stage recovery, thrust vector control and reaction control system design, liftoff drift analysis, communications analysis, umbilical release, acoustics, and design of jettison systems.

\section{Nomenclature}

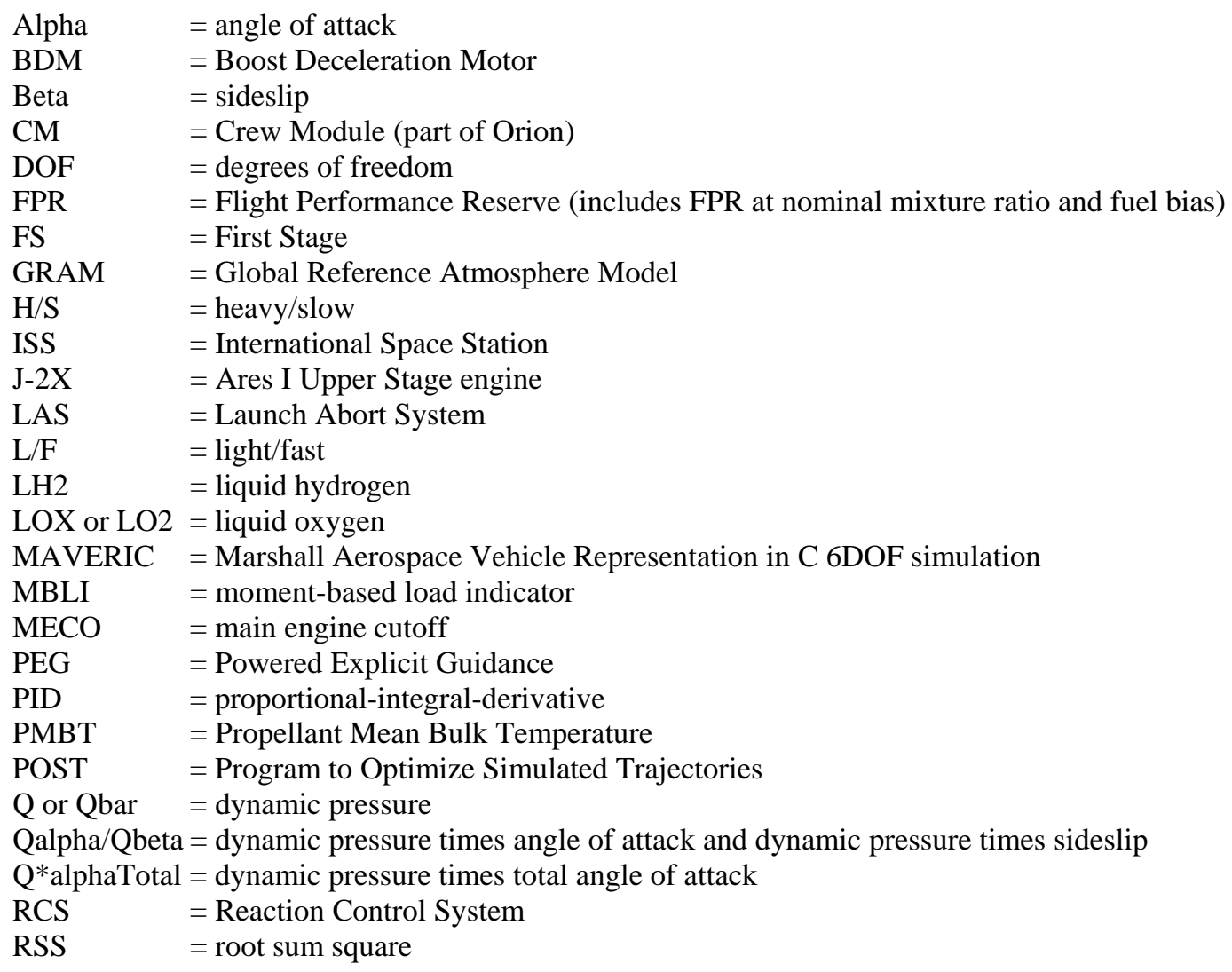

\footnotetext{
${ }^{1}$ Aerospace Engineer, Flight Mechanics \& Analysis Division/EV40, AIAA Member.

${ }^{2}$ Aerospace Engineer, Control Systems Design \& Analysis Branch/EV41, non-AIAA Member.
}

1

American Institute of Aeronautics and Astronautics 
TVC $\quad=$ Thrust Vector Control

US $\quad=$ Upper Stage

\section{Introduction}

The Ares I launch vehicle is currently planned for first test flight in 2013, with crewed flights to the International Space Station (ISS) one or two years later. The crew will fly onboard the Orion spacecraft that Ares I takes to orbit. The Ares I launch vehicle is currently at the Preliminary Design Review stage. The current schedule is subject to delay depending on the funding profile available (and has already been delayed due to budget considerations). Ares I is being designed so that, some time later, it will also be able to take Orion into a low-inclination orbit for rendezvous with the Ares V-delivered Earth Departure Stage and Lunar Surface Access Module (which one would be launched first has not been determined). The two missions (ISS and lunar) have differing payload requirements for Ares I, which leads to slightly different flight profiles and trajectory attributes. Ares I uses a Shuttle-derived 5segment solid rocket booster, with a new Upper Stage that has an Apollo-derived J-2X engine. These two stages are used to insert the Orion into a $-11 \times 100 \mathrm{~nm}$ orbit at a mean altitude of $70 \mathrm{~nm}$. Orion uses its on-board propulsion to circularize at $100 \mathrm{~nm}$ and to proceed on its mission from there. Since the perigee is negative, the Ares Upper Stage naturally burns up upon re-entry with the debris falling in the Indian Ocean.

A large NASA effort is ongoing for design of the Ares I. Contractors ATK (First Stage), Boeing (Upper Stage), Pratt \& Whitney/Rocketdyne (Upper Stage Engine), and Boeing (Instrument Ring) are supporting the design effort along with NASA support contractors. During vehicle design, a high-fidelity 6-degree-of-freedom simulation is where the vehicle is functionally integrated in order to determine whether the design will be able to achieve the goals envisioned. This simulation resides within the guidance, navigation, and control discipline areas, because the simulation is used to develop the guidance and control approaches and to demonstrate that they can fly the integrated vehicle successfully in the presence of expected navigation uncertainties and vehicle and environmental variations. In order to demonstrate that the vehicle will be successful, the simulation must be exercised in ways that demonstrate how much the flight can vary. For example, what is the trajectory that will lead to the worst structural loads that the vehicle will have to withstand? What trajectory will lead to the worst aerothermal environments? And so on.

One way to develop "design" trajectories (or worst-case trajectories for design) is to vary individual parameters between their extremes, and to stack them with each other in single simulations, to see how the vehicle flies as a result. A problem with this approach is that it is quite difficult to determine how statistically bad the resulting simulation is. Another approach, which is more available currently than in the past due to computer speed, is to run Monte Carlo simulations. In this approach, everything that is known to vary is randomly varied across its range and a large number of simulations are run. After the simulations are finished, the results show statistically what the various parameters do. A user may choose the $99 \%$ value for design, or the $95 \%$ value, or the $99.73 \%$ value with 90\% confidence (also called 10\% consumer risk), as desired depending on how much design surety is required.

The approach used in this paper is to run the MAVERIC (Marshall Aerospace Vehicle Representation in C) simulation in Monte Carlo mode to answer the necessary design questions. Besides developing the simulation capability for the launch vehicle, and determining the vehicle and environmental uncertainties appropriate for the simulations, it is necessary to decide what vehicle models to use for the baseline that is being varied. At an early design stage, vehicle models are not what they will be when they are built and tested, so it is critical that heavier and slower models be simulated (for determining parameters such as payload performance and tower clearance) as well as lighter and faster models (for maximum aeroheating and structural loads, among other needs). Another reason to model more sluggish and more sporty vehicle models is that manufactured components will differ in ways that can be measured prior to launch. Engines vary and will be put on test stands prior to vehicle assembly, masses vary and components will be weighed, and solid propellant grain varies and will be tested.

When it comes to failures, with crewed systems, abort capability is necessary. Understanding how the vehicle behaves dynamically in situations where a failure causes dynamic deviation is another necessary analysis. Knowing what will happen depends on understanding how the trajectory and attitude can vary, and again Monte Carlo simulations offer a reliable approach. These simulations help to evaluate various abort triggers for use as abort cues, and also help to determine how much time is available for escape.

This paper discusses first the simulation and modeling of Ares I used in MAVERIC, without describing each model in detail. Next the paper describes the uncertainty modeling and the determination of what simulations are needed (along with the corresponding vehicle models). The customers for the Monte Carlo results are listed, followed by an overview of many of the products and their uses. 


\section{Simulation and Modeling of Ares I}

The MAVERIC simulation models the Ares I launch vehicle in high fidelity, and the fidelity level will increase as the project progresses. The guidance and control algorithms are modeled as they are intended to be incorporated into the flight software. The control approach is described elsewhere ${ }^{1,2,3}$. In brief, the guidance uses an open-loop phase (pitch, yaw, and roll versus altitude) followed by a closed-loop design. An optimization procedure ${ }^{4}$ and linear tangent steering were evaluated for the closed-loop design. The current baseline is the Shuttle version of linear tangent steering, Powered Explicit Guidance ${ }^{5}$ (PEG). Comparison between the two closed-loop approaches did not show any advantages for the more complicated optimization approach. Some reasoning for choosing PEG as opposed to a more advanced guidance appears in Ref. 6. Another reason that advanced methods were not chosen for guidance or for flight control is that the Ares I launch vehicle is intended to use technology advances only where necessary. Guidance functions adapt to adjust the trajectory plan for the changing azimuth through the launch window. A steering function acts between the guidance and control to make sure that the guidance commands will not result in large attitude or attitude rate errors to the control system and that the rate and acceleration commands to control will be limited. This is critical in order to keep from causing actuator hard-over commands from the flight control that could lead to loss of stability. By staying within the control limits, overshoot of the desired attitudes is also minimized. The flight control design for pitch and yaw is a classical proportional-integral-derivative (PID) controller that uses rate gyros on multiple vehicle locations along with mathematical filters in order to control the vehicle in the presence of its vibrational modes. The control design for the reaction control system (RCS) is a phase plane design.

Navigation is currently modeled with sensor models that have initialization error and accelerometer and gyro errors that cause cumulative state vector error as the vehicle ascends into orbit. The error parameters included in the current model will be listed later in the paper. More advanced navigation models are being prepared for upcoming versions of MAVERIC. Ares I navigation is discussed in more detail in Ref. 7. MAVERIC contains models of the propellant slosh and of the flex (vibrational) behavior that have been checked against independent models. The thrust vector control dynamics models are based on Shuttle experience applied to Ares I. A dynamic thrust vector uncertainty model is also included. Propulsion modeling is as furnished by the Ares I propulsion experts. Since the First Stage uses Shuttle-heritage capabilities, the modeling of the First Stage propulsion is very well known. Besides modeling the overall thrusts and flow rates during the two stages, MAVERIC models in detail the uncertainties in shutdown for the First Stage and in startup and shutdown for the Upper Stage. This is because the modeling if these is very important to analyzing the success of stage separation and of orbit insertion accuracy and attitude control after insertion.

For stage separation, MAVERIC models the various components (booster deceleration motors, propellant settling motors, booster tumbling motors, and the dimensions of the vehicle components that must separate) along with uncertainties in the performance of the different components, the direction their thrust is pointing, various lateral and axial forces and torques that interact with the vehicle at this time, and failure cases associated with each component. MAVERIC outputs clearances during the simulation so that the success of the stage separation event can be examined. MAVERIC models the J-2X plume effects on the First Stage after separation, to support analysis of First Stage recovery. Stage separation is also currently being modeled in an independent simulation called CLVTOPS.

MAVERIC models time latencies and RCS behavior. Integration step size is currently 0.005 seconds, in order to correctly model the vibrational modes effects on the GN\&C. MAVERIC does not model the sub-system behavior of the various systems, but rather only models the behavior of systems that lead to effects on the overall vehicle dynamics. For example, the voting logic within the flight computers is not modeled, but the error in output that ultimately influences the vehicle is modeled. MAVERIC does not model aeroelastic effects. MAVERIC models the vehicle as a rigid body in terms of generating forces and torques (although the effects of vehicle flex on the flight control are modeled). Aeroelastic effects are evaluated by the structural analysis discipline. MAVERIC models light to moderate wind gusts using the Global Reference Atmosphere Model (GRAM) ${ }^{8}$ 2007. Extreme wind gusts are taken into account by the structural analysis discipline.

\section{Uncertainties}

Uncertainties can be divided into two categories: those that are unknown now but will be known before flight day, and those that are unknown when the vehicle launches. Items in the first category include a certain portion of the First Stage burn rate uncertainty (the grain used in the flight vehicle is tested before flight), some mass 
uncertainty (including manufacturing uncertainty since components will be weighed, and including some current levels of design mass uncertainty), a portion of the axial force coefficient (assuming that wind tunnel tests and higher fidelity vehicle models improve on knowledge of this parameter), and some of the uncertainty in $\mathrm{J}-2 \mathrm{X}$ performance (the engine will be hot-fired prior to flight).

Parameters in the flight day unknown category (the second category) include remaining unknowns for the items in the first category, navigation uncertainties, dynamic thrust direction uncertainties, and many others. Although all the aerodynamic parameters have larger uncertainty now than they will on flight day, only axial force coefficient affects the overall payload performance and items such as maximum dynamic pressure directly. The rest of the aerodynamic parameters are primarily of interest to control system design as far as dynamic simulation is concerned. The control system must be able to control the vehicle with the full range of aerodynamic parameter uncertainty, whether the vehicle model is heavy/slow or light/fast. For this reason, the aerodynamic parameters other than axial coefficient are all considered to be flight day unknowns.

Since a mean monthly wind profile is being used to design Ares I trajectories and since the payload will not be changed each day after the wind is measured several hours before launch, the wind variations within a month are considered to be "flight day unknowns". Similarly, the First Stage Propellant Mean Bulk Temperature (PMBT) variation during a month is considered as a flight day unknown. Also, since the plan is to fully load the propellant tanks and not offload based on some knowledge of J-2X mixture ratio uncertainty derived during the engine test, all of the mixture ratio uncertainty is considered as flight day uncertainty and goes into calculation of the flight performance reserve (FPR), that amount of extra propellant needed to ensure the orbital delivery is made even with all the uncertainties included. Table 1 lists the uncertainties that are known before launch and that can be used in the trajectory design. Table 2 lists the parameters that are modeled with flight day uncertainty. Some parameters appear in both tables because, of the total uncertainty, some will be determined before flight. The list of uncertainties covered continues to increase as the design matures.

Table 1. Deterministic Parameters (Known Prior to Flight Day). Includes parameters that still have some uncertainty on flight day but are known better by then than they are now. Also includes parameters that vary from vehicle to vehicle but are known better once the vehicle is assembled.

\begin{tabular}{|c|c|c|}
\hline First Stage burn rate & J-2X thrust & J-2X specific impulse \\
\hline Axial forebody coefficient & First Stage dry mass & Interstage dry mass \\
\hline Upper Stage dry mass & J-2X mass & Orion mass \\
\hline Program manager's reserve & & \\
\hline
\end{tabular}

\section{Vehicle Model Choices and Monte Carlo Simulations}

In order to decide what combination of vehicle models, missions, months of launch, and any other parameters are needed for obtaining the necessary results, previous Monte Carlo runs were used, run for each month of the year, for both missions, and for other differing conditions. Three target parameters were identified for analysis.

1. Performance. What combination yields the lowest vehicle performance? This case drives the derivation of the FPR, since other cases would result in more fuel left over than this case. The goal is to find the worst combination of heavy and slow (underperforming) that might make up a known vehicle combination. This case also drives the liftoff drift analysis since it is most sluggish in leaving the launch pad. This vehicle is called H/S in the following discussion.

2. Loads. What combination yields the lightest and fastest vehicle that we might need to fly? This case drives the highest maximum dynamic pressure, the highest structural loads, the highest acceleration, the highest heat rates, the fastest liftoff for umbilical release analysis, worst-case aborts within the atmosphere, and probably the worst-case First Stage gimbal angles and rates. This vehicle is called L/F in the following discussion.

3. Upper Stage acceleration. The Orion spacecraft design has panels that encapsulate the Service Module during atmospheric ascent and carry structural loads during this portion of flight. These panels are jettisoned once the high heating part of ascent is finished, and the rest of the Service Module/Spacecraft Adapter has to carry the remaining structural load for Upper Stage flight into orbit. The highest axial acceleration for Ares I is during First Stage flight, but for this particular purpose we need the highest acceleration that occurs during Upper Stage flight. This occurs with a light/fast Upper Stage and a light payload along with a heavy/slow First Stage (which leads to the Upper Stage having to do more of the 
work and results in a lower amount of remaining propellant and thus an even lighter Upper Stage). This vehicle model is called "hybrid" in the following discussion.

Table 2. Flight Day Uncertainty Parameters

\begin{tabular}{|c|c|c|c|}
\hline $\begin{array}{l}\text { First Stage internally } \\
\text { generated roll torque }\end{array}$ & TVC-induced roll torque & $\begin{array}{l}\text { Dynamic thrust vector } \\
\text { uncertainty }\end{array}$ & $\begin{array}{l}\text { Flex frequency (first } \\
\text { mode) and amplitude }\end{array}$ \\
\hline Uncertainty in mode shape & $\begin{array}{l}\text { Mode slope at the gimbal } \\
\text { point }\end{array}$ & $\begin{array}{l}\text { Slosh mass, location, } \\
\text { damping, and frequency }\end{array}$ & $\begin{array}{l}\text { First Stage Propellant } \\
\text { Mean Bulk Temperature } \\
\text { PMBT (variation within } \\
\text { the month) }\end{array}$ \\
\hline First Stage burn rate & $\begin{array}{ll}\text { First Stage loaded } \\
\text { propellant }\end{array}$ & $\begin{array}{l}\text { First Stage specific } \\
\text { impulse }\end{array}$ & First Stage tailoff model \\
\hline First Stage engine location & $\begin{array}{ll}\text { First Stage engine } \\
\text { alignment }\end{array}$ & $\begin{array}{l}\mathrm{J}-2 \mathrm{X} \text { mixture ratio, thrust, } \\
\text { and specific impulse }\end{array}$ & $\begin{array}{l}\mathrm{J}-2 \mathrm{X} \text { thrust misalignment } \\
\text { and engine location }\end{array}$ \\
\hline $\begin{array}{l}\text { J-2X shutdown transient } \\
\text { thrust profile }\end{array}$ & 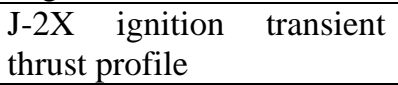 & J-2X shutdown delay time & J-2X shutdown side load \\
\hline $\begin{array}{l}\text { Effect of engine inlet } \\
\text { pressure and temperature } \\
\text { on engine parameters }\end{array}$ & $\begin{array}{l}\text { Variation of engine inlet } \\
\text { pressure and temperature } \\
\text { (oxygen and hydrogen) }\end{array}$ & $\begin{array}{l}\text { Loaded propellant (oxygen } \\
\text { and hydrogen) }\end{array}$ & $\begin{array}{l}\text { Total stack aerodynamics } \\
\text { (axial, normal, lateral, } \\
\text { pitch/yaw/roll moments) }\end{array}$ \\
\hline $\begin{array}{lr}\text { Upper Stage } & \text { stack } \\
\text { aerodynamics } & \text { (moment } \\
\text { and force terms) } & \end{array}$ & $\begin{array}{l}\text { Navigation initialization } \\
\text { (position, velocity, and } \\
\text { attitude) }\end{array}$ & $\begin{array}{l}\text { Accelerometer errors (bias } \\
\text { repeatability, scale factor, } \\
\text { misalignment, noise, each } \\
\text { axis) }\end{array}$ & $\begin{array}{lr}\text { Gyro errors } & \text { (bias } \\
\text { repeatability, scale } & \text { factor, } \\
\text { misalignment, random } \\
\text { walk, each axis) }\end{array}$ \\
\hline $\begin{array}{l}\text { Atmospheric density, } \\
\text { temperature, pressure }\end{array}$ & Winds aloft & $\begin{array}{l}\text { RCS fuel per tank, thrust, } \\
\text { flow rate, plume effects, } \\
\text { moment arm, each stage }\end{array}$ & $\begin{array}{l}\text { Boost Deceleration motors } \\
\text { BDM (burn rate, PMBT, } \\
\text { ignition interval, loaded } \\
\text { propellant, thrust vector } \\
\text { alignment) }\end{array}$ \\
\hline $\begin{array}{l}\text { Mass } \\
\text { uncertainties in all dry } \\
\text { masses, center of mass, } \\
\text { inertia }\end{array}$ & $\begin{array}{l}\text { Uncertainty in J-2X plume } \\
\text { effect on FS after } \\
\text { separation }\end{array}$ & $\begin{array}{l}\text { Propellant settling motors } \\
\text { (burn rate, PMBT, loaded } \\
\text { propellant, ignition } \\
\text { interval, thrust alignment) }\end{array}$ & $\begin{array}{l}\text { Thrust vector control } \\
\text { (scale factor, damping } \\
\text { ratio, position limit, rate } \\
\text { limit, position error at } \\
\text { startup) }\end{array}$ \\
\hline $\begin{array}{l}\text { J-2X TVC: time to gimbal } \\
\text { capability }\end{array}$ & $\mathrm{J}-2 \mathrm{X}$ engine inertia & $\begin{array}{l}\text { Boundary of } \mathrm{J}-2 \mathrm{X} \text { engine } \\
\text { nozzle while in interstage, } \\
\text { including misalignment } \\
\text { and vibration }\end{array}$ & $\begin{array}{lll}\text { Upper Stage } & \text { TVC } \\
\text { misalignment } & \end{array}$ \\
\hline $\begin{array}{l}\text { Time delay to stage } \\
\text { separation }\end{array}$ & $\begin{array}{l}\text { First stage nozzle pointing } \\
\text { error when in null position }\end{array}$ & $\begin{array}{l}\text { Center of mass/center of } \\
\text { percussion uncertainty }\end{array}$ & $\begin{array}{l}\text { Side force from First Stage } \\
\text { thrust at staging }\end{array}$ \\
\hline
\end{tabular}

Table 3 shows the combinations of models for obtaining the desired results, along with what each run is targeting. Flying to different parts of the rendezvous launch window does not in general affect the flight parameters significantly. Since the lunar mission has a 90-minute design launch window, an extra case must be run in order to understand the effect of the launch window on the Upper Stage impact footprint. The 10-minute ISS launch window does not have a significant effect on the impact footprint. The ISS mission has a lighter payload, so its loads and heating parameters are typically slightly worse than for the lunar mission. In some previous studies, August was the worst month for dynamic pressure, but July was the worst for heating, so both are on the list. For each Monte Carlo set, 2000 random simulations were made.

The approach to designing the three different vehicle models was to take the various parameters that are in the pre-flight-determined category (Table 1) and to determine the partial derivative of the item of interest with respect to each parameter. For example, for First Stage burn rate, the partial of payload with respect to burn rate supplies the necessary information for the H/S model, the partial of maximum dynamic pressure with respect to burn rate supplies the L/F model, and the partial of Upper Stage maximum acceleration with respect to burn rate supplies the hybrid model. It should be noted that worst dynamic pressure does not necessarily imply the other goals of the 
light/fast model will be met. For example, the worst-case vehicle model for maximum acceleration may not be the same as that for maximum dynamic pressure. This nuance was not considered for the current vehicle modeling, but will be in the future.

Table 3. Combinations of Vehicle/Mission Models for Generating Monte Carlo Worst Cases

\begin{tabular}{|c|c|c|c|c|c|}
\hline $\begin{array}{l}\text { Veh } \\
\text { icle }\end{array}$ & $\begin{array}{l}\text { Mis } \\
\text { sion }\end{array}$ & $\begin{array}{l}\text { Mont } \\
\mathrm{h}\end{array}$ & \begin{tabular}{|r|} 
Lau \\
nch \\
window
\end{tabular} & What is the need? & $\begin{array}{l}\text { Ident } \\
\text { ifier }\end{array}$ \\
\hline $\mathrm{L} / \mathrm{F}$ & ISS & $\begin{array}{c}\text { Aug } \\
\text { ust }\end{array}$ & $\begin{array}{l}\text { Clo } \\
\text { se }\end{array}$ & Max Q, max acceleration, FS footprint & $\begin{array}{l}\text { TD6- } \\
\text { A }\end{array}$ \\
\hline $\mathrm{L} / \mathrm{F}$ & $\begin{array}{l}\text { Lun } \\
\text { ar }\end{array}$ & $\begin{array}{c}\text { Febr } \\
\text { uary }\end{array}$ & $\begin{array}{l}\begin{array}{c}\text { Clo } \\
\text { se }\end{array} \\
\end{array}$ & Dynamic pressure*total angle of attack, MBLI & $\begin{array}{l}\text { TD6- } \\
\mathrm{B} \\
\end{array}$ \\
\hline $\mathrm{H} / \mathrm{S}$ & $\begin{array}{l}\text { Lun } \\
\text { ar }\end{array}$ & $\begin{array}{c}\text { Febr } \\
\text { uary }\end{array}$ & $\begin{array}{l}\text { Clo } \\
\text { se }\end{array}$ & Worst performance, FPR, liftoff drift, US footprint & $\begin{array}{l}\text { TD6- } \\
\mathrm{C}\end{array}$ \\
\hline $\mathrm{H} / \mathrm{S}$ & $\begin{array}{l}\text { Lun } \\
\text { ar }\end{array}$ & $\begin{array}{c}\text { Febr } \\
\text { uary }\end{array}$ & $\begin{array}{l}\text { Ope } \\
\mathrm{n}\end{array}$ & Worst performance, FPR, liftoff drift, US Footprint & $\begin{array}{l}\text { TD6- } \\
\mathrm{D} \\
\end{array}$ \\
\hline $\begin{array}{l}\text { hyb } \\
\text { rid }\end{array}$ & ISS & $\begin{array}{c}\text { Febr } \\
\text { uary }\end{array}$ & $\begin{array}{l}\text { Ope } \\
\mathrm{n}\end{array}$ & Worst US acceleration & $\begin{array}{l}\text { TD6- } \\
\mathrm{E}\end{array}$ \\
\hline $\mathrm{L} / \mathrm{F}$ & ISS & $\begin{array}{c}\text { Febr } \\
\text { uary }\end{array}$ & $\begin{array}{l}\begin{array}{c}\text { Clo } \\
\text { se }\end{array} \\
\end{array}$ & $\begin{array}{l}\text { Dynamic pressure*total angle of attack, MBLI, compare with lunar, } \\
\text { US footprint }\end{array}$ & $\begin{array}{l}\text { TD6- } \\
\mathrm{F}\end{array}$ \\
\hline $\mathrm{L} / \mathrm{F}$ & ISS & July & $\begin{array}{l}\text { Ope } \\
\mathrm{n}\end{array}$ & heat rate, compare with L/F August & $\begin{array}{l}\text { TD6- } \\
\text { G }\end{array}$ \\
\hline $\mathrm{L} / \mathrm{F}$ & $\begin{array}{c}\text { Lun } \\
\mathrm{ar}\end{array}$ & $\begin{array}{c}\text { Aug } \\
\text { ust }\end{array}$ & $\begin{array}{l}\text { Ope } \\
\mathrm{n}\end{array}$ & Max Q, max acceleration, comparison between ISS and lunar & $\begin{array}{l}\text { TD6- } \\
\mathrm{H}\end{array}$ \\
\hline
\end{tabular}

Table 4 shows the effects of the various pre-flight-determined quantities on the parameters of interest for the three vehicle models described above. It is easy to see which parameters have a large impact on the vehicle models. It is also easy to see that some of the parameters could be zeroed out without much effect. The J-2X performance parameters affect the maximum dynamic pressure because the entire trajectory is re-optimized to take the model changes into account.

Table 4. Parameter Effects for Vehicle Model Definitions (Heavy/Slow, Light/Fast, and Hybrid)

\begin{tabular}{|c|c|c|c|}
\hline Parameter & $\begin{array}{l}\text { Payload effect for } 1 \text { sigma } \\
\text { positive variation (lb) }\end{array}$ & $\begin{array}{l}\text { Maximum dynamic } \\
\text { pressure effect for } 1 \text { sigma } \\
\text { positive variation (psf) }\end{array}$ & $\begin{array}{l}\text { Upper Stage maximum } \\
\text { accel. effect for } 1 \text { sigma } \\
\text { positive variation (g) }\end{array}$ \\
\hline First Stage burn rate & 317 & 15.93 & -0.009 \\
\hline $\mathrm{J}-2 \mathrm{X}$ thrust & 273 & 1.75 & 0.014 \\
\hline J-2X specific impulse & 228 & -0.06 & -0.007 \\
\hline Drag coefficient & -153 & -4.89 & 0.004 \\
\hline First Stage mass & -78 & -0.81 & 0.002 \\
\hline Interstage mass & -3 & -0.03 & 0.000 \\
\hline Upper stage mass & -97 & -0.17 & -0.000 \\
\hline $\mathrm{J}-2 \mathrm{X}$ mass & -28 & -0.05 & 0.000 \\
\hline Ares margins_-ISS/lunar & $\begin{array}{l}\text { Assumed allocated to mass } \\
\text { for heavy vehicle model }\end{array}$ & $-1.44 /-1.37$ & $-0.0008 /-0.0005$ \\
\hline $\begin{array}{c}\text { Program reserve- } \\
\text { ISS/lunar }\end{array}$ & $\begin{array}{c}\text { Assumed required to take } \\
\text { to orbit for heavy vehicle } \\
\text { model }\end{array}$ & $-0.54 /-0.75$ & $-0.0012 /-0.0018$ \\
\hline Orion mass_-ISS/lunar & $\begin{array}{c}\text { Maximum required mass } \\
\text { used }\end{array}$ & $-1.02 /-0.51$ & $-0.0023 /-0.0004$ \\
\hline $\begin{array}{c}\text { 99.73\% RSS effect- } \\
\text { ISS/lunar }\end{array}$ & 1,437 (lunar only) & $47.0 / 46.9$ & $0.052 / 0.052$ \\
\hline
\end{tabular}


The vehicle model chosen is one that yields a 99.73\% variation in the parameter of interest from the mean value. Since this vehicle model is made up of a number of variations, there is a multi-dimensional choice as to what combination of parameters is chosen that causes the $99.73 \%$ variation. Once the $99.73 \%$ value is determined (Table 4), the vehicle model that leads to the most likely vehicle is the one chosen. Any parameters with uniform distributions are taken at their maximum values, since each value is equally likely. Taking the maximum value for the uniformly distributed parameter means that Normally-distributed parameters do not need to contribute as much to the overall result, and so are closer to nominal values. The maximum-likelihood value is then taken for the Normally-distributed parameters, which leads to the parameters that have the largest influence on the result being the ones that are dispersed the most. The result in each case is confirmed by designing a trajectory for the new vehicle model in the trajectory design tool (Program to Optimize Simulated Trajectories-POST).

\section{Customers}

Table 5 lists a partial set of current customers for the Monte Carlo results.

Table 5. Monte Carlo Dispersion Customers

\begin{tabular}{|c|c|c|c|}
\hline Customer & Uses & Customer & Uses \\
\hline Aerothermal & $\begin{array}{l}\text { Plot files (Mach, alpha, beta, etc.); US } \\
\text { re-entry also }\end{array}$ & $\begin{array}{l}\text { Thrust } \\
\text { Vector } \\
\text { Control }\end{array}$ & $\begin{array}{l}\text { Maximum gimbal angles, gimbal rates, } \\
\text { actuator power }\end{array}$ \\
\hline Environments & $\begin{array}{l}\text { Development and verification of } \\
\text { winds modeling }\end{array}$ & Acoustics & Uses standard dispersion output \\
\hline $\begin{array}{l}\text { First Stage } \\
\text { Reentry }\end{array}$ & $\begin{array}{l}\text { First Stage separation } \\
\text { initialize analysis }\end{array}$ & $\begin{array}{l}\text { Main } \\
\text { Propulsion } \\
\text { System }\end{array}$ & $\begin{array}{l}\text { Results of flight performance reserve } \\
\text { analysis; acceleration and fuel dispersions }\end{array}$ \\
\hline $\begin{array}{l}\text { Flight } \\
\text { Mechanics }\end{array}$ & $\begin{array}{l}\text { FPR, orbit insertion accuracy, flight } \\
\text { control analysis, GN\&C requirements } \\
\text { values, upper stage reentry footprint, } \\
\text { navigation accuracy, guidance } \\
\text { analysis, input for liftoff drift, } \\
\text { umbilical removal, adequacy of } \\
\text { RCS/TVC designs }\end{array}$ & Orion Loads & $\begin{array}{l}\text { Trajectory data at Mach } 1 \text {, trajectory data } \\
\text { at max Q, trajectory data at all high } \\
\text { dynamic pressures for loads evaluation, } \\
\text { and trajectory data at various times for } \\
\text { abort analysis. }\end{array}$ \\
\hline Venting & $\begin{array}{l}\text { Plot files; time history plots of alpha } \\
\text { and beta as function of Mach. Alpha } \\
\text { versus beta ellipses }\end{array}$ & $\begin{array}{l}\text { Ares Stage } \\
\text { Separation }\end{array}$ & Stage separation clearance dispersions \\
\hline $\begin{array}{l}\text { Abort } \\
\text { Trajectories }\end{array}$ & $\begin{array}{l}\text { Dispersed states at max dynamic } \\
\text { pressure, First Stage, LAS jettison, } \\
\text { etc. }\end{array}$ & $\begin{array}{l}\text { Aerody- } \\
\text { namics } \\
\text { Panel }\end{array}$ & $\begin{array}{l}\text { Variation of aerodynamic angles for } \\
\text { which various data are needed }\end{array}$ \\
\hline $\begin{array}{ll}\text { Abort } & \text { Test } \\
\text { Booster } & \\
\text { Project } & \end{array}$ & $\begin{array}{l}\text { Mach, alpha, beta, altitude, axial } \\
\text { accel, dynamic pressure at max-drag, } \\
\text { max-dynamic pressure, FS separation, } \\
\text { and LAS jettison flight conditions }\end{array}$ & Orion & $\begin{array}{l}\text { Altitude and acceleration as function of } \\
\text { Mach for dispersions and reference } \\
\text { trajectories, for acoustics. Heat rate at } \\
\text { LAS jettison, conditions at Service } \\
\text { Module panel jettison. }\end{array}$ \\
\hline RCS & $\begin{array}{l}\text { Acceleration angles with respect to } \\
\text { body axes, confirmation that RCS } \\
\text { design is adequate, requirements if not }\end{array}$ & $\begin{array}{l}\text { Structural } \\
\text { Loads }\end{array}$ & $\begin{array}{c}\text { Qalpha/Qbeta ellipses at various altitudes; } \\
\text { list of specific 99.73\% trajectory results; } \\
\text { MBLI results }\end{array}$ \\
\hline ESM Fairing & $\begin{array}{l}\text { Nominal and dispersed data at } \\
\text { Encapsulated Service Module fairing } \\
\text { jettison }\end{array}$ & $\begin{array}{l}\text { Range } \\
\text { Safety }\end{array}$ & $\begin{array}{c}\text { Trajectory envelopes; velocities on the } \\
\text { envelopes }\end{array}$ \\
\hline Fuel slosh & Slosh amplitude and time history plots & $\begin{array}{l}\text { Communi- } \\
\text { cations }\end{array}$ & $\begin{array}{c}\text { Azimuth and elevation to Tracking and } \\
\text { Data Relay satellites }\end{array}$ \\
\hline
\end{tabular}

For some customers where it is not clear which of the Monte Carlo cases provides their worst case, all trajectories are made available and these customers pick what is worst for them by examining outputs of interest. For example, the aerothermal analysis discipline runs the trajectories from the Monte Carlo runs through their thermal evaluation model while examining the heating on various body points. Similarly, for First Stage recovery, a 
separate 6DOF Monte Carlo simulation is used to model the random behavior of the booster as it is re-entering the atmosphere. The large set of state vectors resulting from the post-stage separation point serve as initialization states for the re-entry simulation. There is no current single parameter that can be used to define the worst case for First Stage recovery. Orion uses the Monte Carlo results to determine the statistics of normal vehicle conditions that the spacecraft might need to abort from. The overall statistical results provide the bounds for which the Launch Abort System should be qualified. Other discipline areas, such as acoustics, take the output statistics and examine them for cases that are worst for acoustic design (in this case, load indicators, accelerations, and aerodynamic angles as a function of Mach number). For the various staging or jettison events (stage separation, ullage settling motor jettison, encapsulated service module panel jettison, launch abort system jettison, and Orion separation), the Monte Carlo results provide the range of conditions for which successful clearance and operation must be demonstrated.

\section{Analyses}

\section{A. Load Indicators}

All results below are for a particular set of vehicle design parameters at a stage in the design process and will change as the design is refined. Any parameters that are judged to be outside the acceptable range will be worked during the design process. Figure 1 shows the maximum dynamic pressure variation for the nominal trajectories for the dispersion vehicle models. It can be seen that this indicator is significantly higher for some vehicle/mission combinations than it is for others. Figure 2 shows the variation of maximum dynamic pressure during Monte Carlo runs for the worst case. It is interesting to see how large a Mach range there is for the maximum dynamic pressure. Figure 3 shows the variation of maximum dynamic pressure times total angle of attack ( ${ }^{*}$ alphaTotal), a key structural load indicator, for the worst case. Note that the highest dynamic pressures are seen in the summer, but due to wind variations the highest $\mathrm{Q}^{*}$ alphaTotal is in February. Also of interest is that the highest $\mathrm{Q}^{*}$ alphaTotal is quite a bit larger in 6DOF versus 3DOF simulation. 3DOF simulation captures all the wind variations, but assumes the vehicle is always pointed in the desired direction. When the flight control is included, the high dynamic pressure

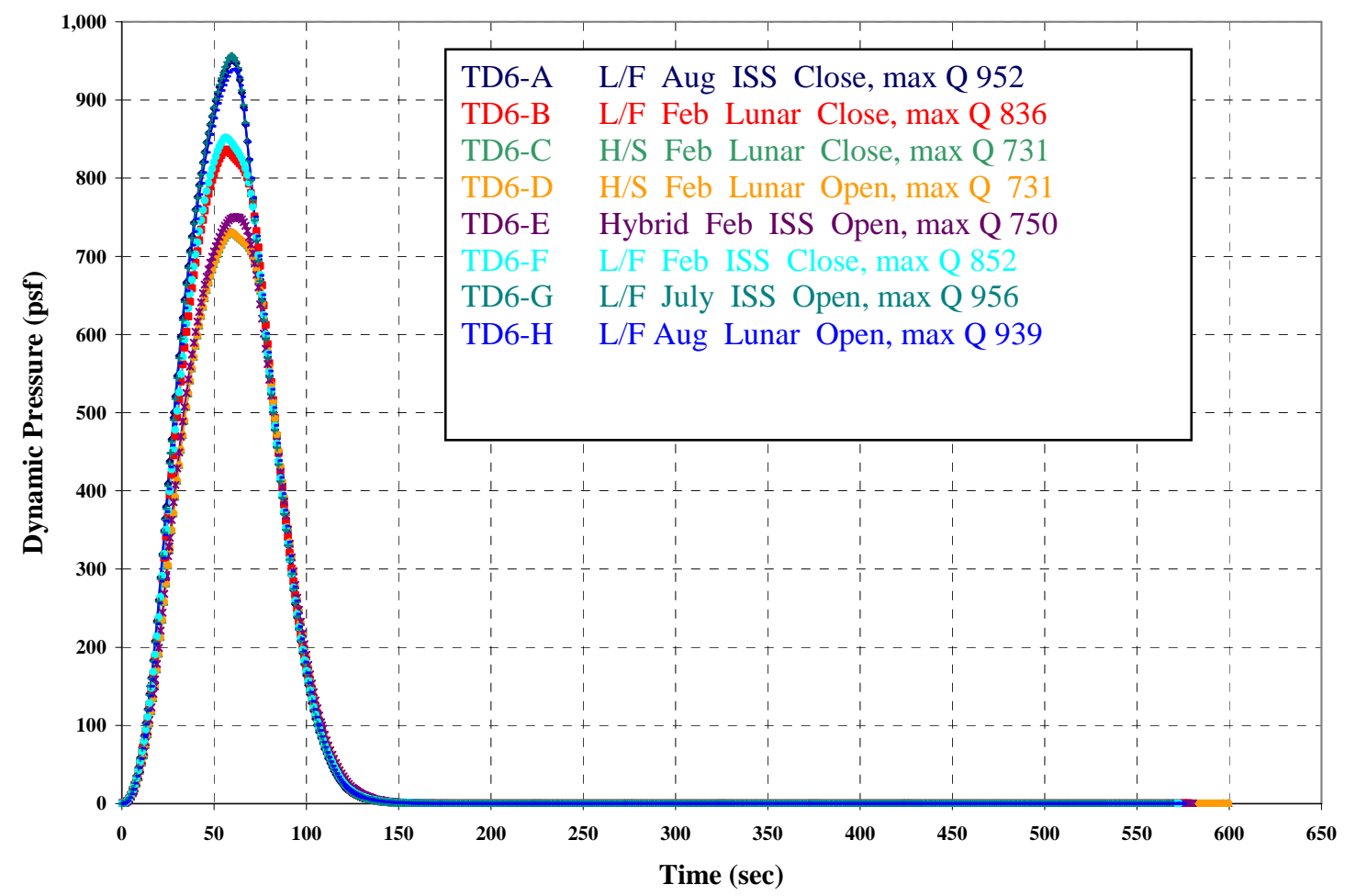

Figure 1. Maximum Dynamic Pressure Variation for Dispersion Nominals. The list of trajectories is in Table 3. 


\section{Max Dynamic Pressure vs. Mach}

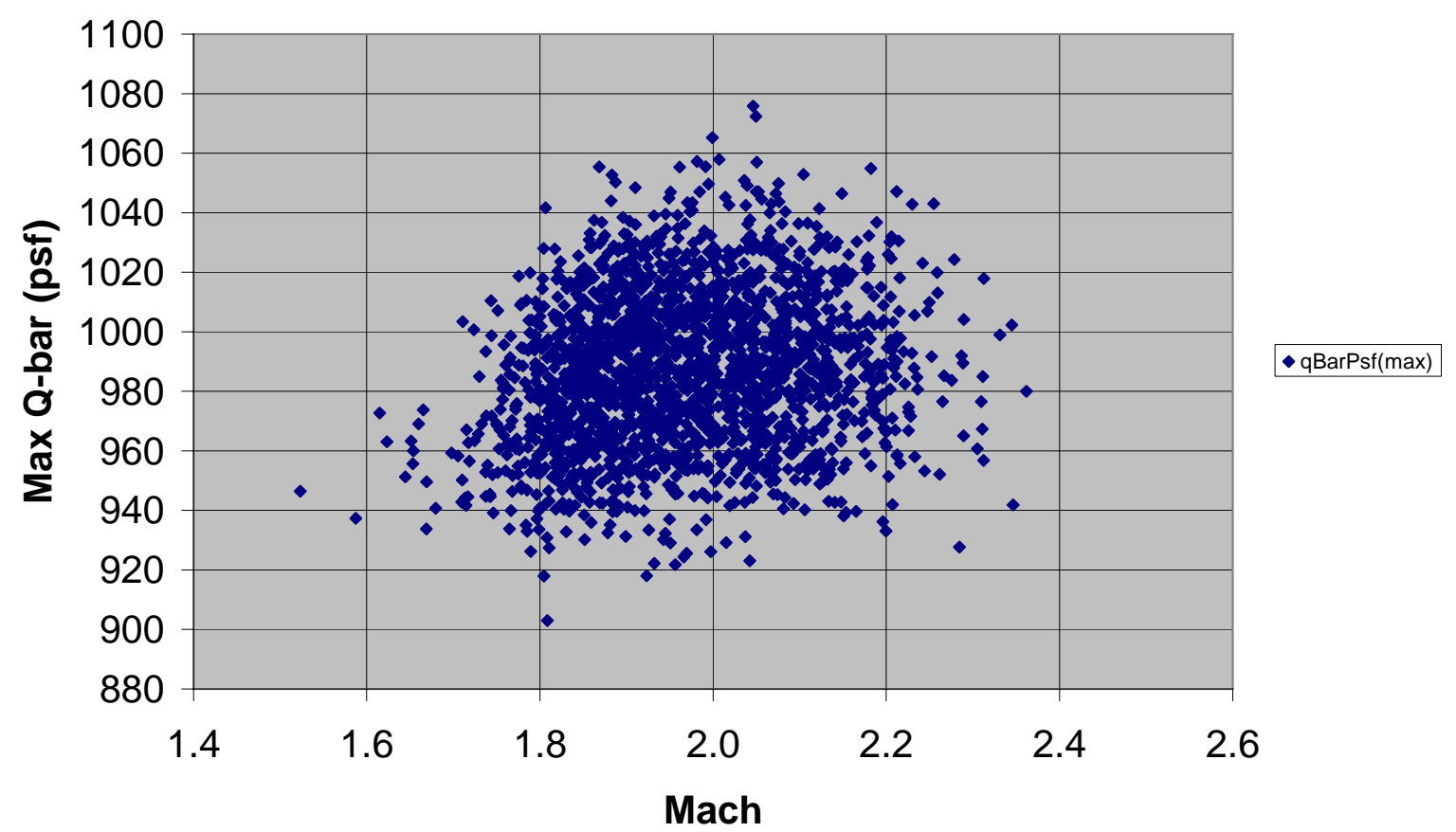

Figure 2. Maximum Dynamic Pressure versus Mach for Highest Dynamic Pressure Case (L/F ISS July)

Max Q-Alpha Total vs. Run Number

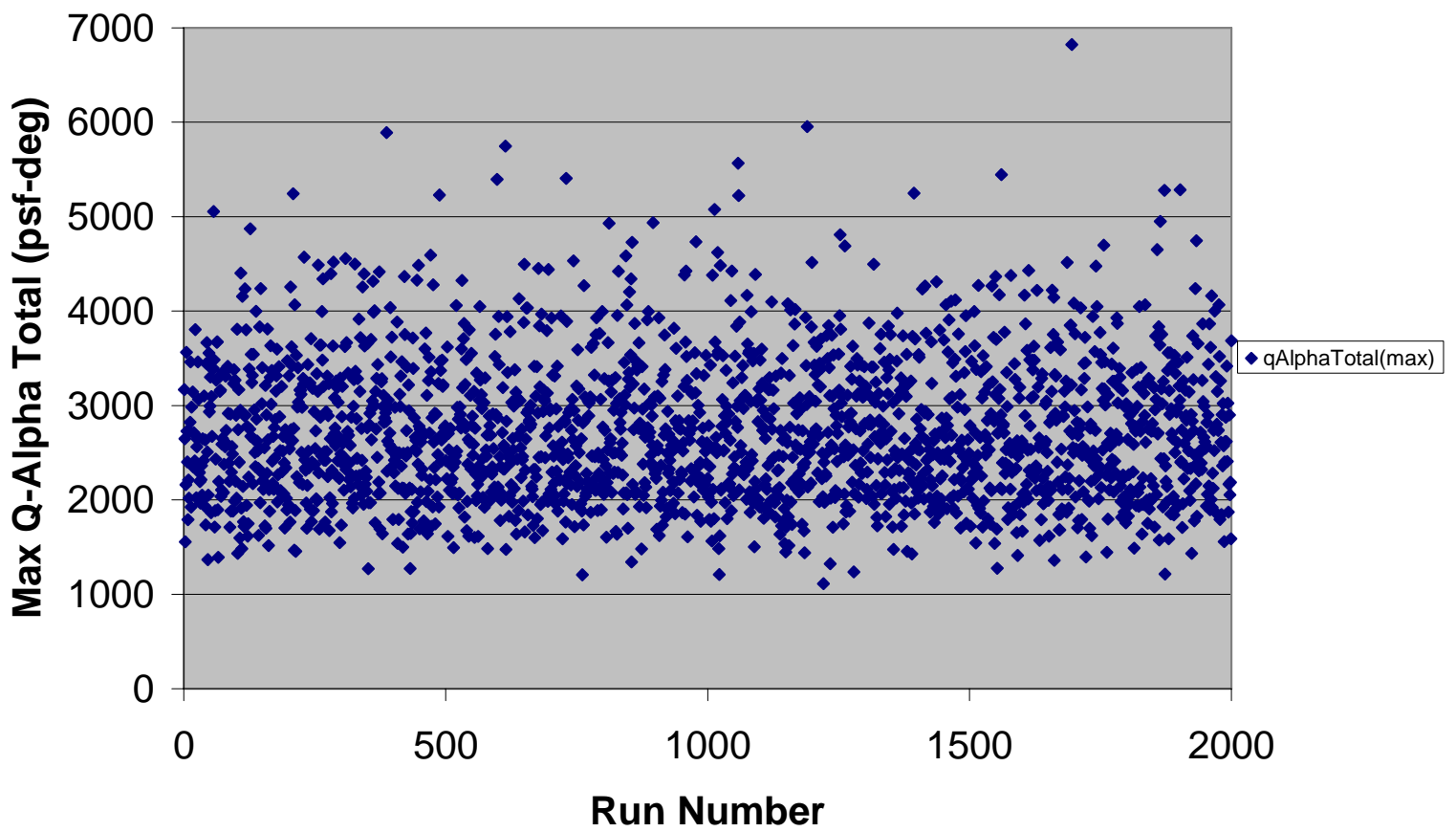

Figure 3. Variation in Peak of Dynamic Pressure times Total Angle of Attack for Worst Case (L/F Lunar February) 
and strong winds make it difficult to fly without attitude error. A degree or two of attitude error at a high dynamic pressure results in a substantial increase in $\mathrm{Q}^{*}$ alphaTotal for the worst cases. A more refined load indicator, called the moment-based load indicator (MBLI), has been derived as a measure of the dynamic load on each portion of the vehicle. MBLI envelopes are shown in Figure 4. The MBLI is normalized so that a value of about 1.0 would imply the vehicle exceeds its load limits and safety margin.

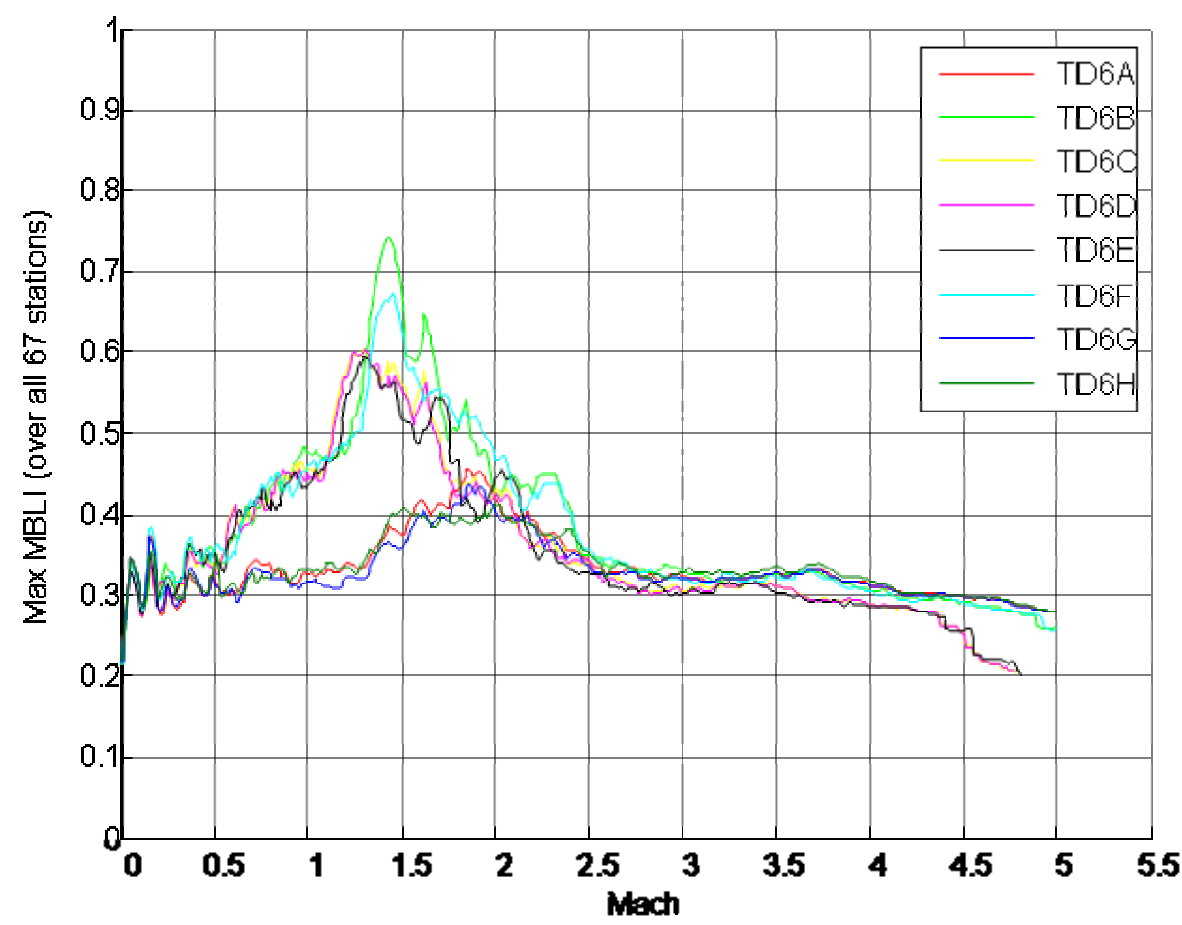

Figure 4. Maximum Moment-Based Load Indicator (MBLI) for all 67 Vehicle Locations and all 2000 Monte Carlo runs

\section{B. Launch Probability due to Winds Aloft}

These results can be used to estimate launch probability due to winds aloft. Suppose the current value of Q*alphaTotal being used for structural design is 6400 psf-deg. If it is assumed that the winds are measured on launch day with a balloon and then the launch occurs within a few hours, a Q*alphaTotal criteria is needed for the go-no go decision. Suppose an increase of up to 600 psf-deg is allocated to wind persistence (the variation of the wind between the measurement and the launch time) and another $400 \mathrm{psf}$-deg is allocated to margin. Then for all simulations where the measured Q*alphaTotal is below 5400 psf-deg using the measured wind, the decision would be go for launch. Using these criteria leads to Table 6 for a particular set of runs. These criteria will need to be refined as the detailed design proceeds.

Table 6. Launch Probability due to Winds Aloft-selected mission models

\begin{tabular}{|c|c|c|c|}
\hline Mission & $\begin{array}{c}\text { Launch Probability } \\
\text { (percent) }\end{array}$ & Mission & $\begin{array}{c}\text { Launch Probability } \\
\text { (percent) }\end{array}$ \\
\hline L/F ISS August & 100 & Hybrid ISS February & 99.95 \\
\hline L/F Lunar February & 99.6 & L/F ISS February & 99.8 \\
\hline H/S lunar February & 99.95 & L/F ISS July & 100 \\
\hline & & L/F Lunar August & 100 \\
\hline
\end{tabular}




\section{Monte Carlo Products}

Besides scatter plots, products from the Monte Carlo dispersion runs include tables of statistics for all parameters of interest (there are currently over 100 of these), statistics of key parameters at each mission event of interest, envelope plots of various parameters (worst case and various percentages), calculations of correlations of the outputs with respect to the various input uncertainties, time histories of parameters, squatcheloids (plots of angle of attack versus sideslip at a particular altitude, or plots of dynamic pressure times each of these aerodynamic angle quantities at various altitudes), and summary comparisons of the different cases.

\section{Fuel Remaining}

Determination as to whether the flight performance reserve (FPR) is sufficient involves examining the worstcase liquid oxygen and liquid hydrogen remaining. If the flight runs out of either of these for more than an allowed number of runs, then some additional propellant must be set aside for FPR and withheld from use in designing nominal flight with maximum payload. Figure 5 shows an example of a way to do this calculation. The desire is to minimize the total amount of propellant (LOX + LH2) needed to meet the required percentage for FPR coverage. The figure shows a scatter plot of propellant remaining for a sample Monte Carlo run. In the case shown, all of the data points show both LO2 and LH2 remaining. This means that FPR can be reduced while still meeting the required success percentage. The two probability curves at the lower left represent propellant remaining for 99.73\% with $10 \%$ consumer risk ( $90 \%$ confidence) and $99.73 \%$ with no consumer risk considered (simply pull the $99.73 \%$ value from the Monte Carlo experimental data). They represent a movement of the origin of the graph that would occur if the total LH2 and LO2 available were changed. If the origin were moved to a point above these curves, there would be quite a few cases that run out of oxygen. If the origin were moved to a point to the right of these curves, hydrogen failures would occur. As these curves are moved to the left and down, they represent adding more propellant and pushing the scatter plot up and to the right. A line segment of constant total propellant remaining is shown. Finding the minimum constant that satisfies the FPR probability requirement will minimize the total propellant needed. Integrating the probability distribution of the remaining propellant and determining the likelihood of running out of propellant allows this constant to be minimized. For the optimum shown, some failure cases are still allowed (shown on the plot).

\section{E. Orbit Insertion Accuracy}

Orbit insertion accuracy is shown in Figs. 6 and 7 (it is generally not impacted significantly by which mission/vehicle model is being flown, except that a longer ascent allows the navigation errors to grow slightly). The orbit plane error is primarily due to the navigation attitude initialization error, and the in-plane energy error is primarily due to the uncertainty in the amount of impulse obtained during the J-2X shutdown transient.

\section{F. Impact Footprint}

Figure 8 shows impact footprint areas for the Upper Stage for the different missions and for various other assumptions as to the altitude where the Upper Stage breaks up and the pieces that it breaks into. The Upper Stage was propagated in 6DOF from the end of the dispersed ascent until the breakup altitude. The toe and heel of the footprint were determined through use of a postulated heavy/low drag piece of debris and a light/high drag piece. These results will be used to help refine the design to ensure that none of the pieces fall on any populated land masses.

\section{G. Stage Separation}

One of the fertile areas for Monte Carlo analysis is stage separation, a key part of ascent that must be examined in detail to ensure success. Monte Carlo analysis for Ares I stage separation is currently being performed in two independent simulations. Figure 9 shows examples of the motion of the outside of the J-2X nozzle with respect to the interstage boundary for two cases, one nominal (with the various uncertainties and variations included) and the other with a boost deceleration motor (BDM) failure. When one BDM fails, a large side torque results that moves the interstage closer to the J-2X nozzle as the interstage is pulled back from the Upper Stage. Despite an expected high reliability for the BDMs, since the vehicle is crewed, it is being designed to succeed even in the presence of a 
failure. These results help in determining what combination of systems and timing will lead to successful separation.

Usable $\mathrm{LO}_{2}$ Remaining vs. Usable $\mathrm{LH}_{2}$ Remaining

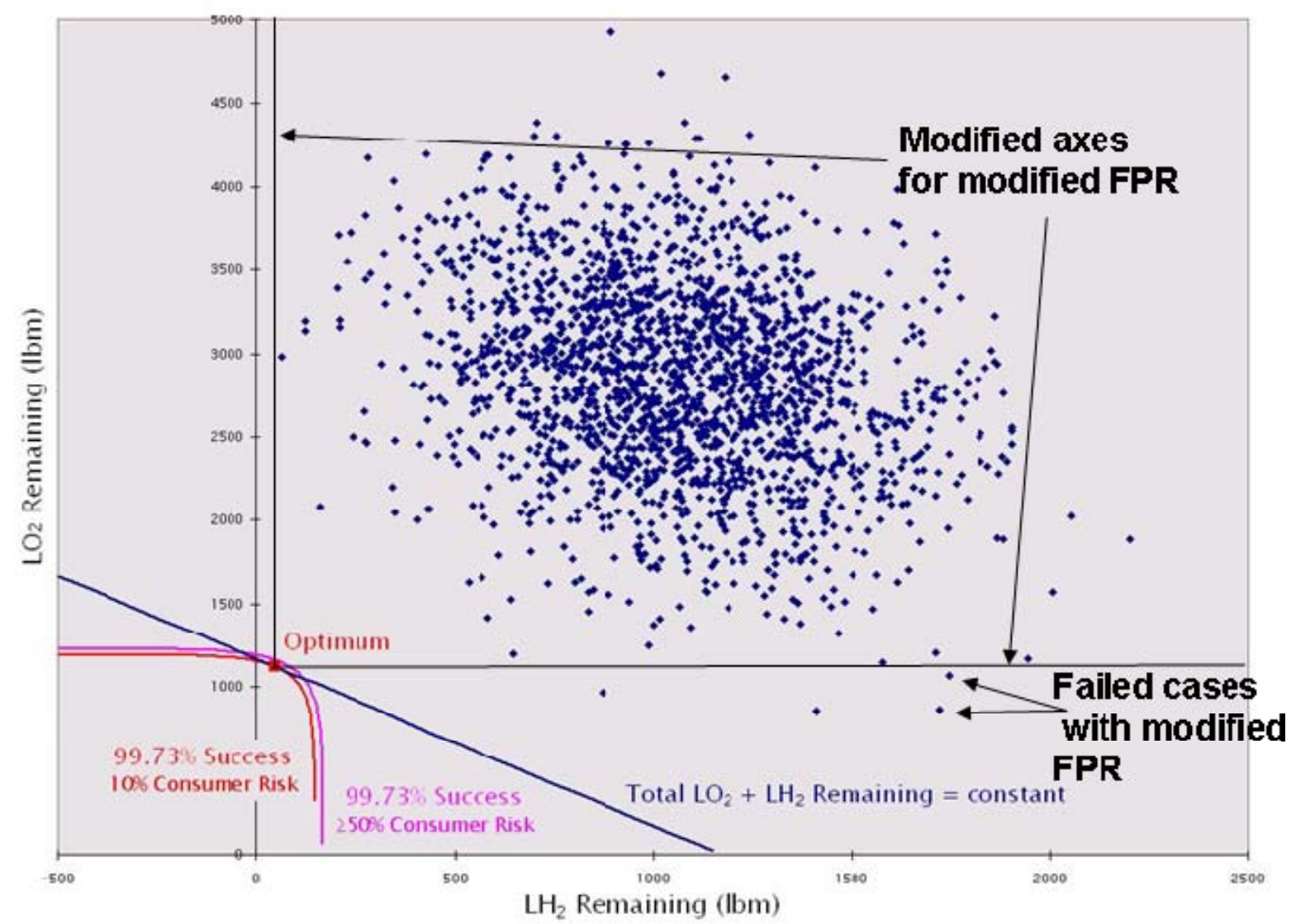

Figure 5. Propellant Remaining and Flight Performance Reserve Calculation Example

\section{H. Failure and Abort Analysis}

Another important area for Monte Carlo analysis is examination of the effects of various failures. Although these failure modes are expected to be unlikely, since the vehicle is crewed, successful abort is desired for any situation where it is possible to abort safely. For any failure that affects vehicle dynamics (for example, a thrust vector control failure that is hard over, fails in place, or fails to null; a nozzle failure; or a First Stage case or field joint burn through), a Monte Carlo run will generate statistics of the starting conditions for the failure (since it can occur at any time on any flight). The value of using various parameters for abort triggers (make the decision to abort if this value is exceeded) can readily be evaluated, as well as the ability to depart from the vehicle before certain structural parameters are exceeded. For example, Fig. 10 shows envelopes for yaw rate around the Monte Carlo runs that were adjusted so that there would be no false alarms even with wind gusts. Figure 11 shows a way Monte Carlo results can be used to analyze aborts. Using the various triggers such as the one shown in Fig. 10, for a particular thrust vector control actuator failure near the time of maximum dynamic pressure, one can measure the time available. In Fig. 11, the first abort trigger limit to be passed is graphed, and the y axis shows the time duration between the moment the trigger value is reached and the structural load indicator limit is exceeded (hence the time available to abort, not considering the possibility of an explosion after the limit is reached).

Figure 12 shows an example of a flight parameter at the presumed time when the crew module and launch abort system (CM/LAS) would depart from the failing launch vehicle (assuming it takes 0.55 seconds after the trigger is passed before the CM/LAS leaves). This information can be used to help with CM/LAS modeling for ensuring the abort will be successful. 
Wedge Angle at CEV Separation vs. Run Number

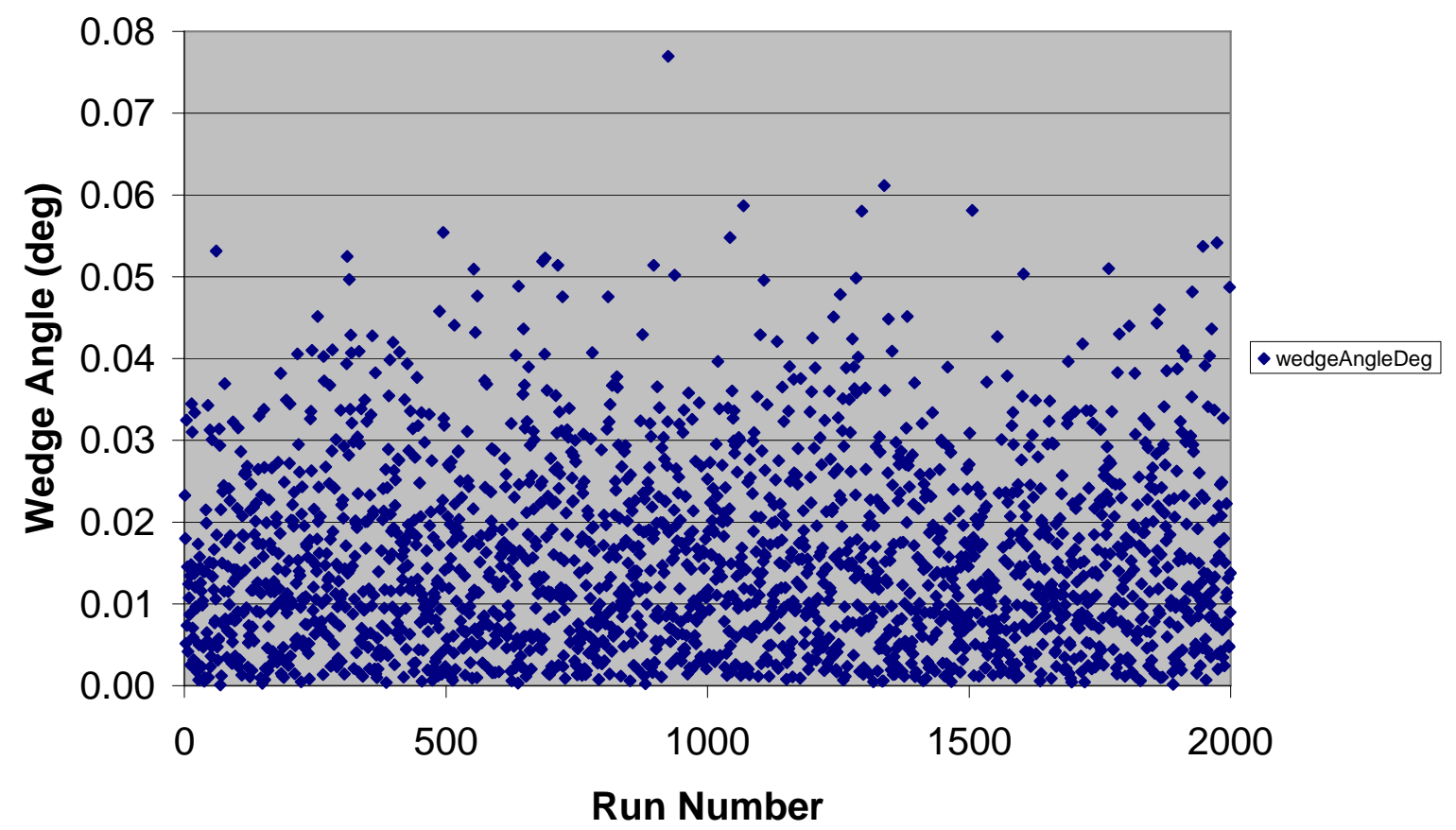

Figure 6. Orbit Plane Error at Insertion

Delta Semi-Major Axis at CEV Separation vs. Run Number

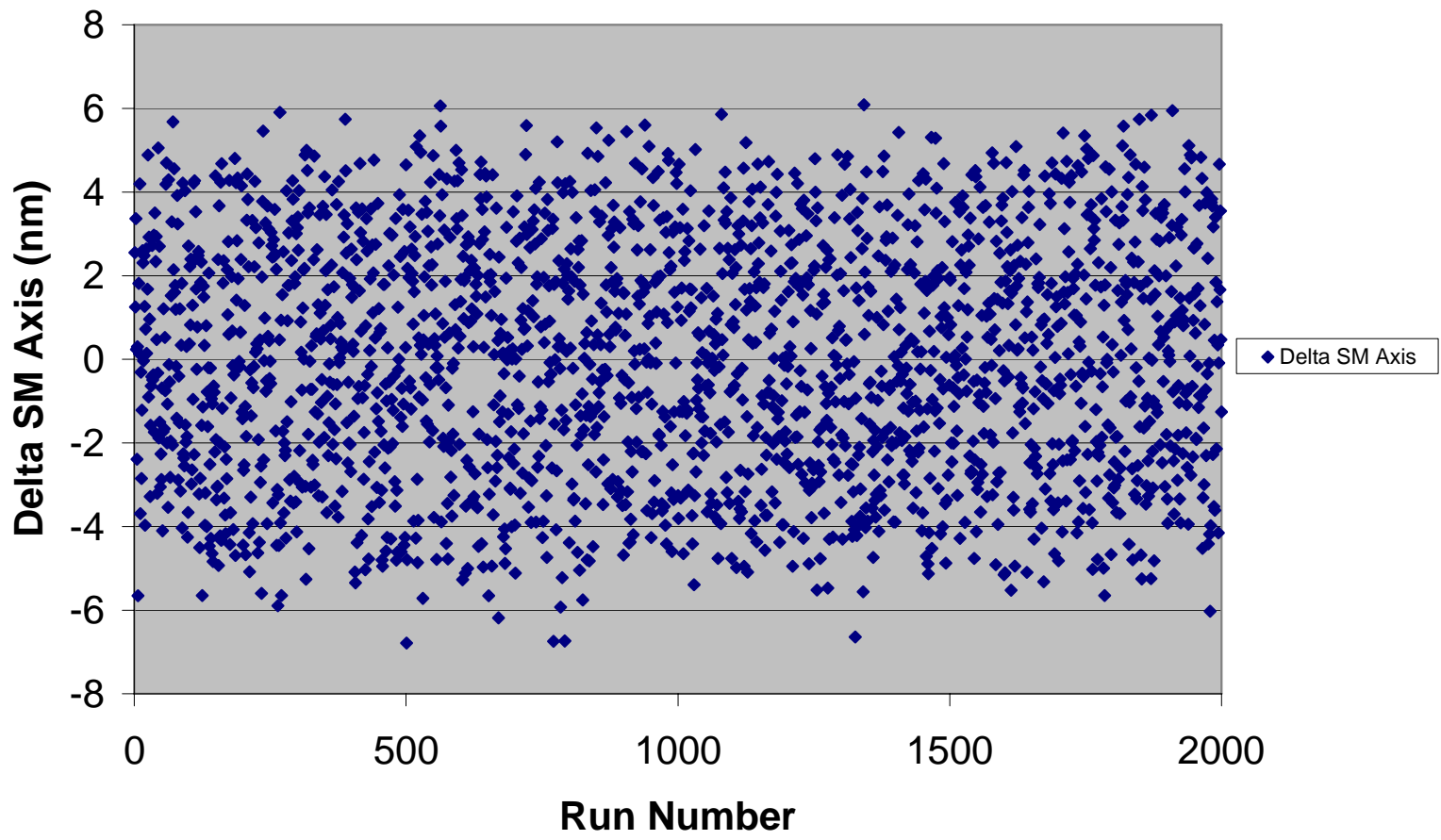

Figure 7. Semi-Major Axis Error at Insertion 


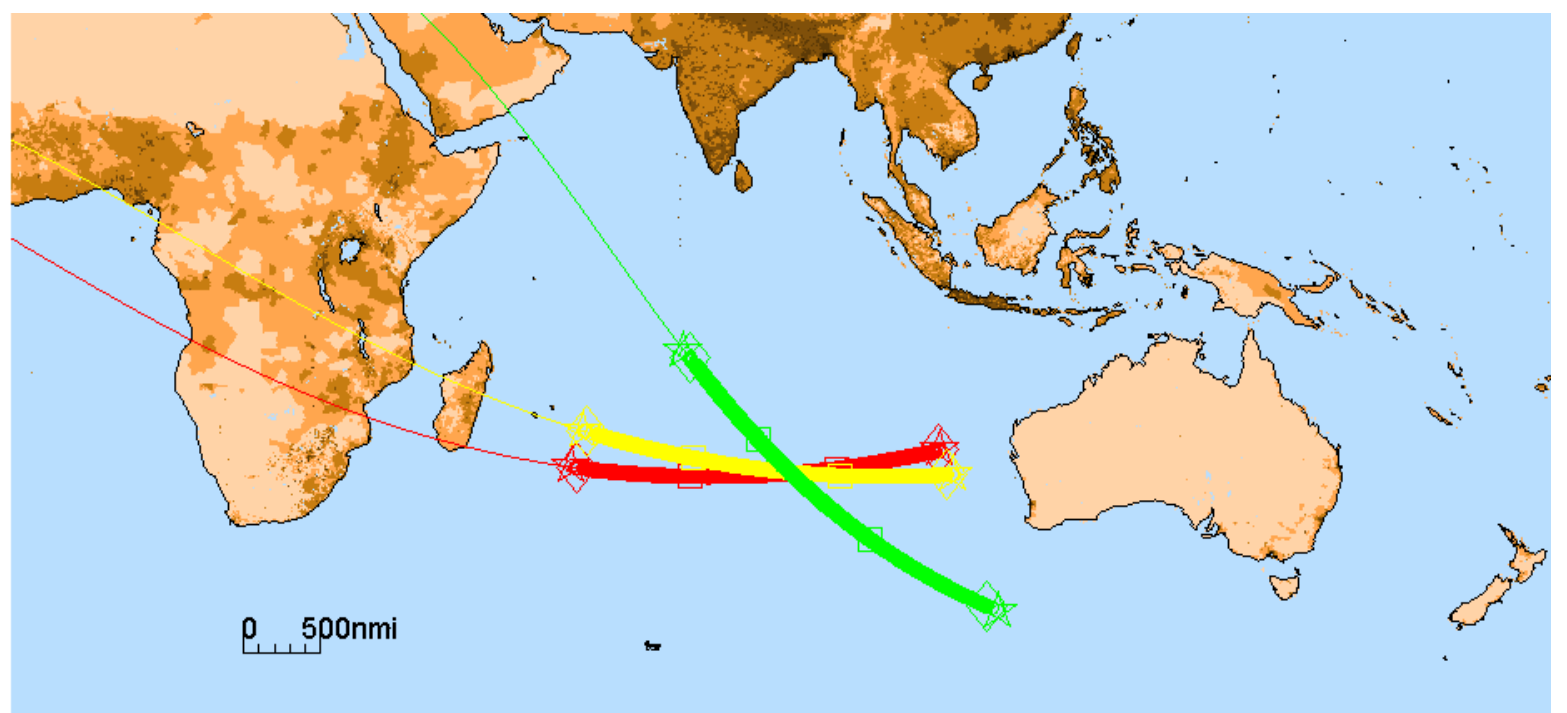

Figure 8. Upper Stage Impact Footprint Areas. Yellow = lunar mission, open of launch window, red = lunar mission, close of launch window, green = ISS mission, open of launch window, stars are worst case results, diamonds are $99.73 \%$ values with 90\% confidence, squares are mean impact points of the high and low drag pieces.
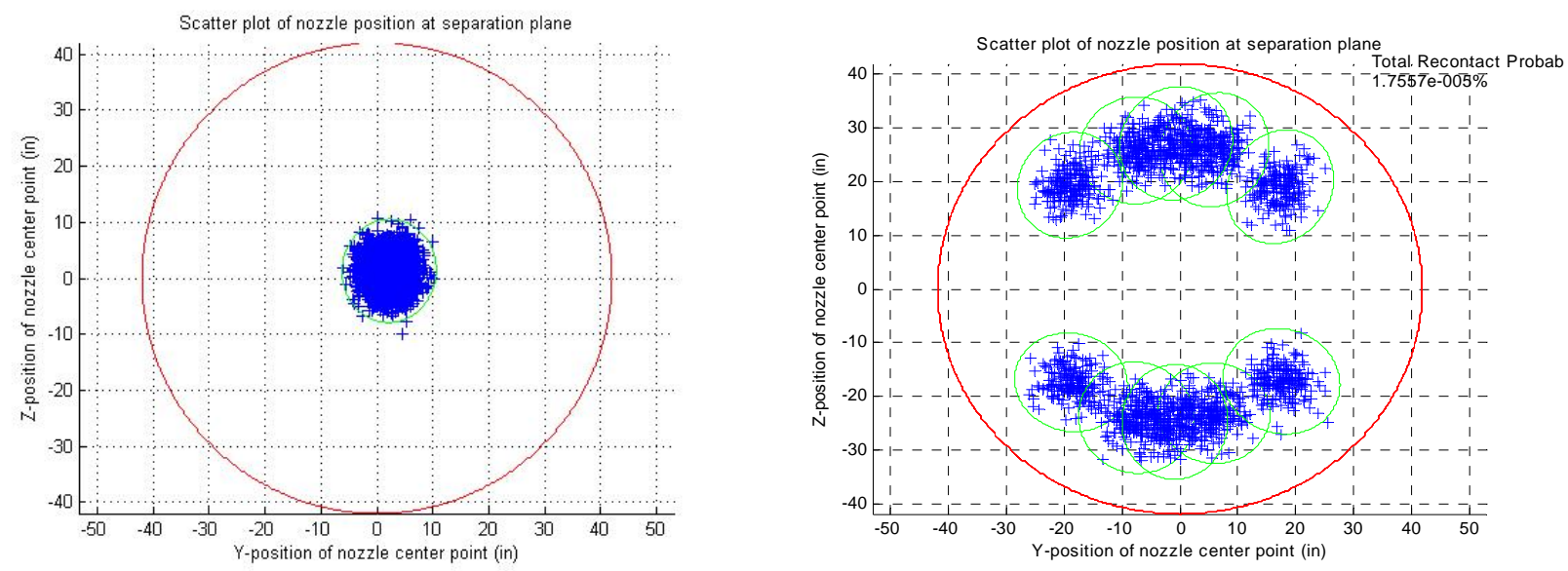

Figure 9. Stage Separation Monte Carlo Results. Left graph is no-failure case, right is one Boost Deceleration Motor failure. The outer circle represents the interstage that, if contacted, would damage the J-2X nozzle. The blue Monte Carlo marks indicate the nearest approach of the outside of the nozzle to the interstage. Clearance between the nozzle and the interstage is 42 inches at the start of the stage separation. The green ellipses are $99.73 \%$ ellipses.

\section{Guidance Analysis}

Monte Carlo analysis was also used to determine the guidance approaches that are best for Ares I. As an example of this, Monte Carlo runs were used to compare the use of different open-loop guidance independent variables. The guidance commands in the open-loop table are pitch, yaw, and roll. They may be a function of time, altitude, Mach number, speed, or other parameters. Analysis showed that time was not as good a parameter as a state variable, but that it did not matter much which state variable was used. This result agrees with Ref. 6. Altitude is currently being used since it is monotonic through staging. Monte Carlo analysis was also used to compare the Shuttle closed-loop guidance (Powered Explicit Guidance) ${ }^{5}$ to a more complete optimization process as a closedloop guidance approach. In addition, Monte Carlo analysis was used was used to compare various limits on guidance-commanded attitude rates and attitude accelerations for their affects on the flight control. 


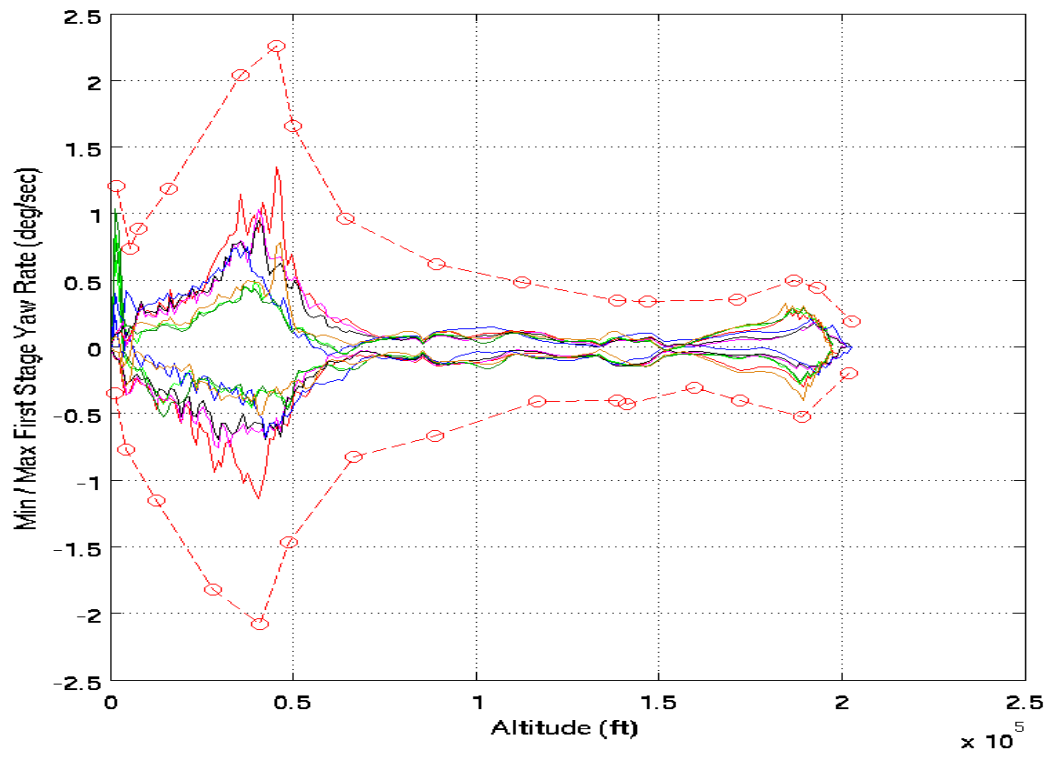

Figure 10. Yaw Rate Envelopes for Monte Carlo Runs (solid curves) and Abort Trigger Envelope (dashed curve)

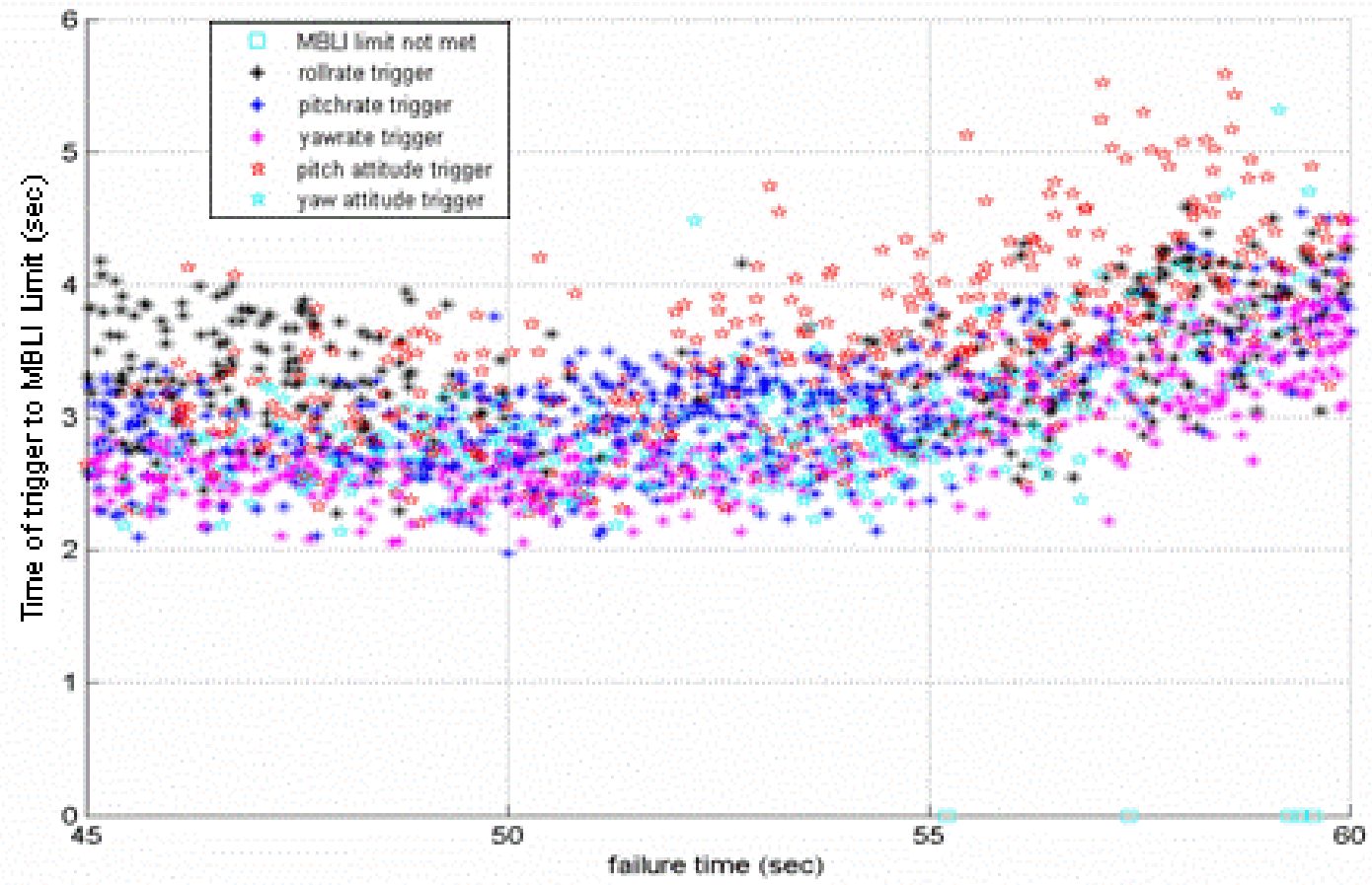

Figure 11. Time Available Before Vehicle Structural Failure After Abort is Triggered with Thrust Vector Control Failure. The failure mode was both actuators failing in place at their current value. Zero on the $y$ axis represents the time the first trigger value is passed, some time after the failure occurs. The first trigger to be exceeded is indicated for each Monte Carlo run on the plot. MBLI limit not met means that the load limit was never reached for those particular cases (blue squares at zero on the y axis). So in general the crew has at least 2 seconds to depart from the vehicle before structural limits are reached. 


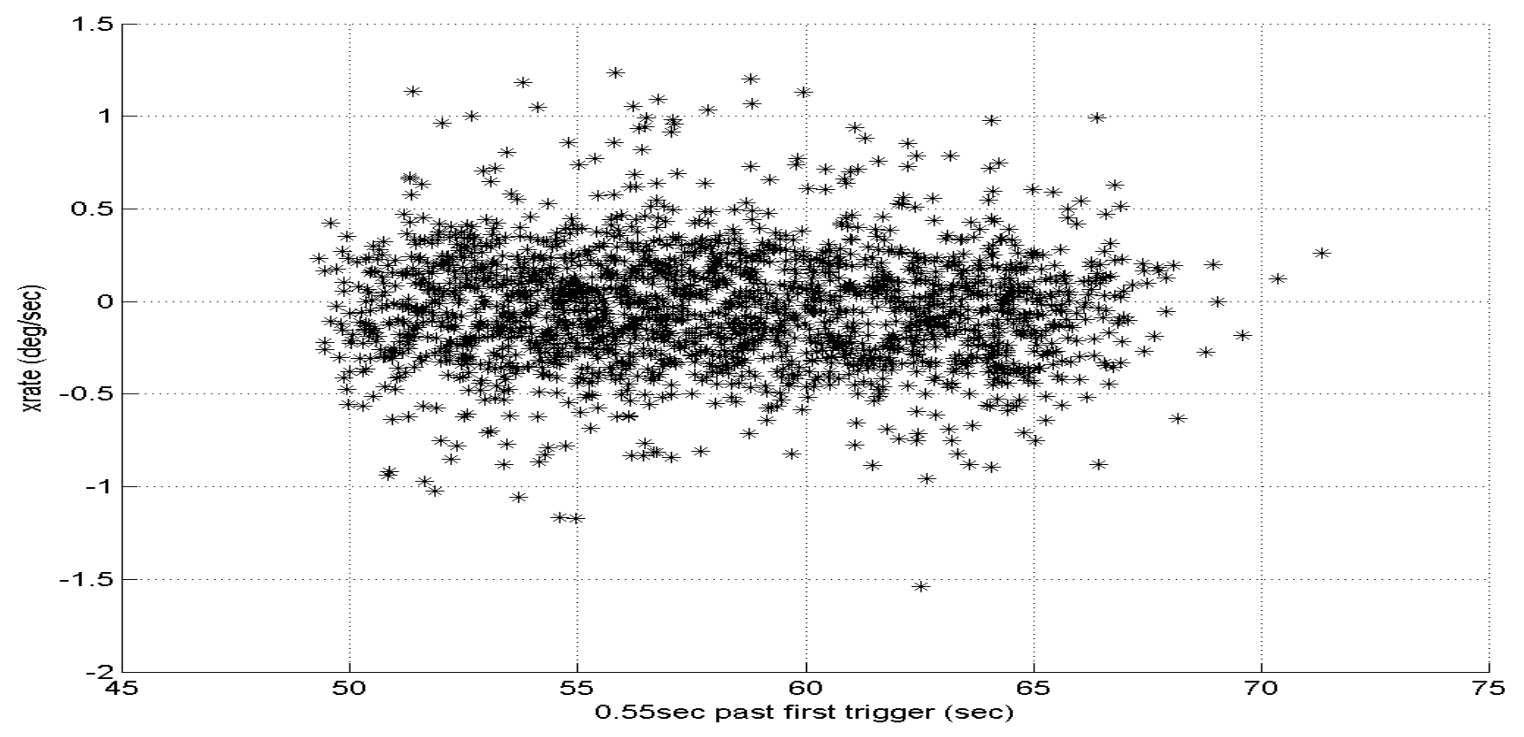

Figure 12. Attitude Rate at the Presumed Time of CM/LAS Separation from the Launch Vehicle for the Thrust Vector Control Errors in Figure 11. Time of flight is on the x-axis. These data can be used to assist in $C M / L A S$ design for abort.

\section{J. Flight Control Analysis}

Development of the flight control design for each design cycle starts with stability analysis. Gains are derived that provide stability (along with the flex filters) and sufficient time response in the linear system. The flight control design is tested in the nonlinear, 6DOF time simulation (MAVERIC) to show that it successfully flies the vehicle and to verify stability and transient response characteristics. Many potential issues are discovered before the use of Monte Carlo simulations. But until all the uncertainties are encountered (winds, aerodynamic moments, TVC errors, lag times, etc.), it is not possible to be sure the flight control will succeed in general. When issues are found in the Monte Carlo results, they can be chased down in the runs that led to the problems. For example, Fig. 13 shows the yaw error envelope for Upper Stage flight (the red line is the nominal case). The errors at the start of Upper Stage flight result from transients due to the coast during staging before J-2X startup and due to the closed-loop guidance commands for steering to a different attitude. The significant error at the end of Upper Stage flight, just prior to insertion, was less understandable. The vast majority of runs had an error less than 1.5 deg at insertion, but many were higher than this value. It was determined that the integral gain was far too low to cover certain cases where dispersions were combined in a way that increased yaw disturbance torque towards the end of powered flight. The attitude integral gain was increased and the stability analysis repeated to verify margins. As can be seen in Fig. 14, this portion of the error can be removed with some work in the control design.

Another example is in Figs 15-16. Although some error is unavoidable if the vehicle is to remain stable (and since the winds are changing), some Monte Carlo runs show high error around 80 seconds into flight (Fig. 15). Similar to the upper stage anomaly, bad combinations of vehicle dispersions compounded by bad winds caused larger than expected pitch errors in this portion of flight. With some adjustment of the attitude proportional gain, this is improved (Fig. 16).

\section{Conclusion}

This paper describes how Monte Carlo simulation is being used to understand many of the issues involved with designing the Ares I launch vehicle. Starting with high fidelity simulation along with uncertainties in each input parameter of interest, the simulations needed are defined in order to examine worst case design points for each discipline area. Besides helping with vehicle design parameters, the simulation also assists with determining whether the design meets requirements in many integrated vehicle areas. Many of these were described in the paper. 
As the Ares I design matures, with each passing month, more uses for the data output from the Monte Carlo runs are discovered as the various subsystems look for their design cases. After the design is firm, Monte Carlo simulation will be used to assist in verifying that the Ares I meets its requirements.

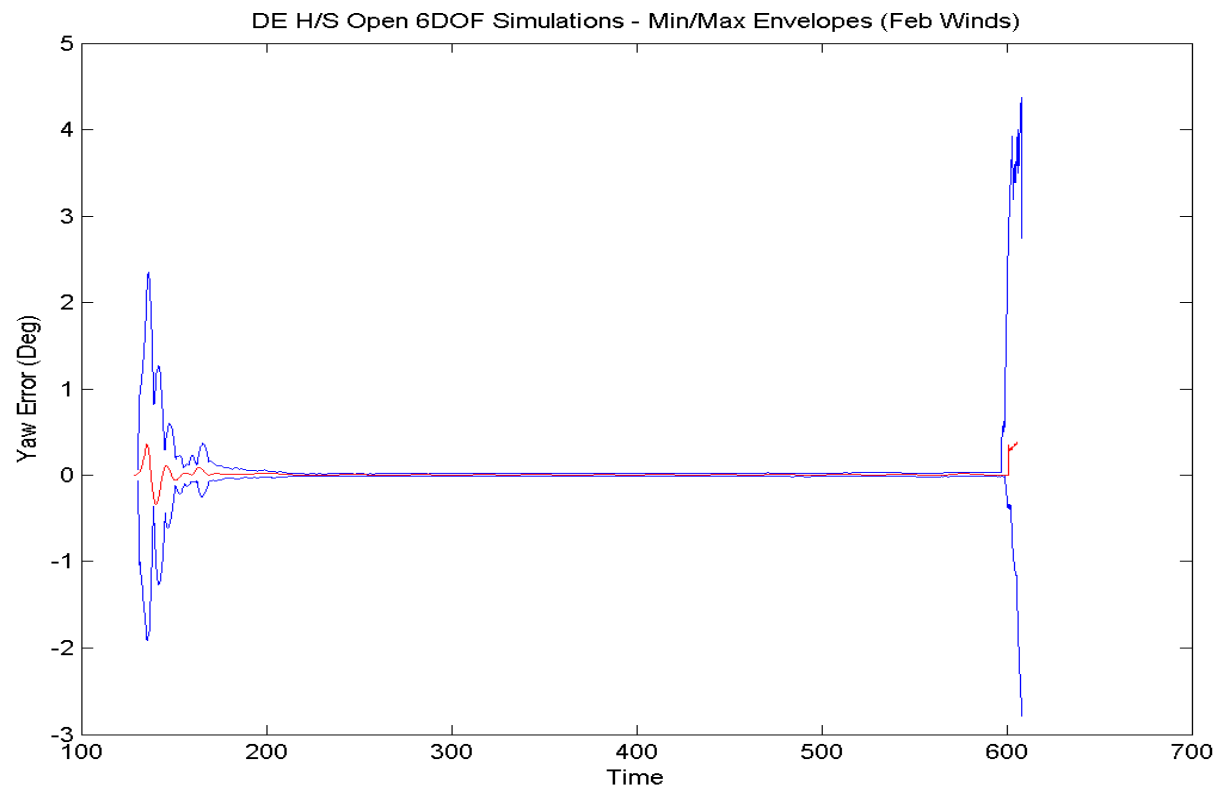

Figure 13. Yaw error before flight control adjustment (lunar February H/S mission). This graph is for Upper Stage flight. The early excursions are expected from attitude deviations associated with stage separation as well as the closed-loop guidance commanding an attitude maneuver once it begins issuing commands. A few out of the 2000 Monte Carlo runs had significant attitude errors near MECO, although the vast majority of cases had less than 1.5 degrees error.

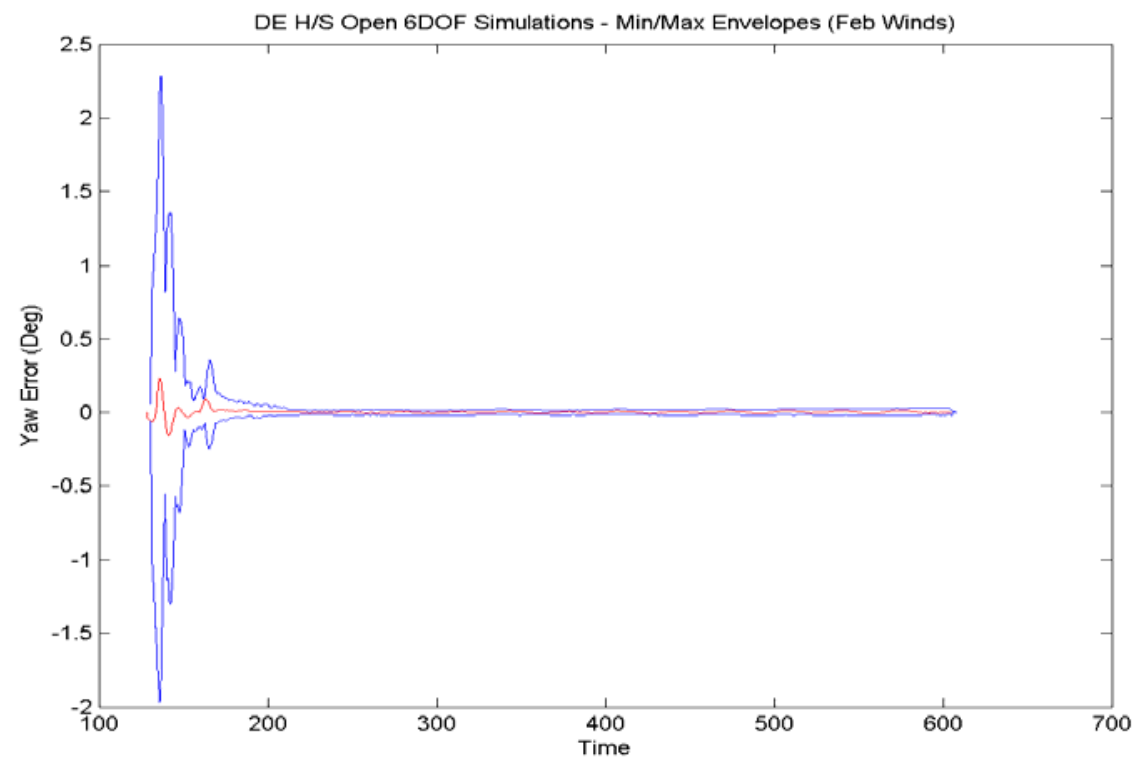

Figure 14. Yaw error after flight control adjustment for the case in Fig. 13. Note the improvement at the end of flight. 


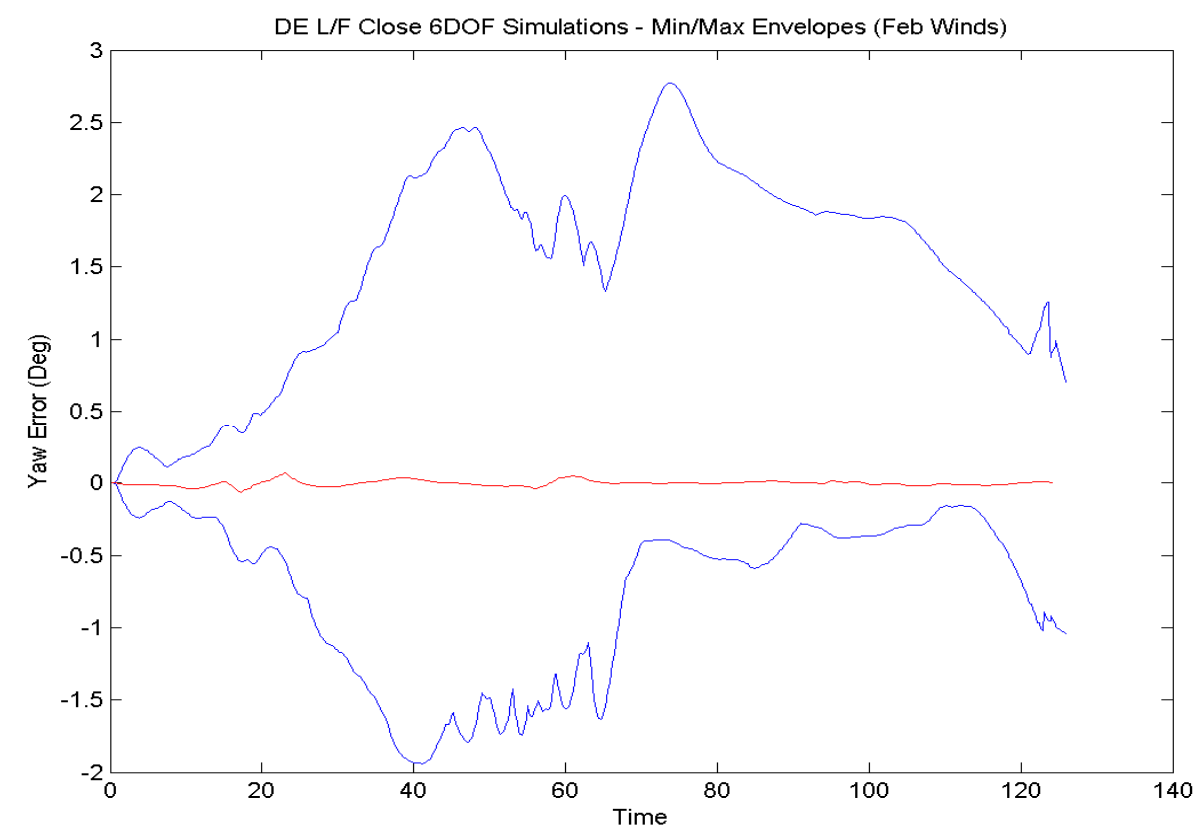

Figure 15. Yaw Error Envelope (and nominal) Prior to Flight Control Adjustment (L/F lunar February mission)

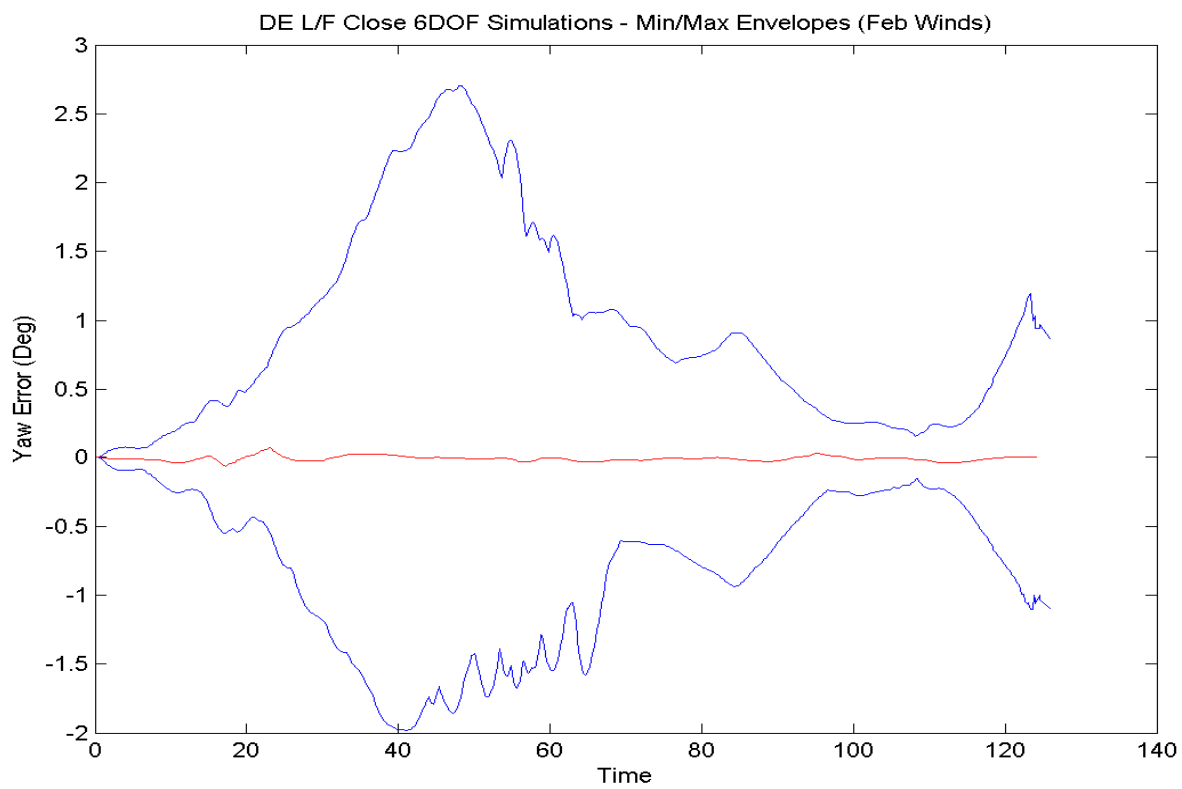

Figure 16. Yaw Error Envelope (and nominal) after Flight Control Adjustment (L/F lunar February mission)

\section{Acknowledgments}

The authors thank the Ares GN\&C team for producing the results shown in this paper. In particular, the authors are grateful to Stan Douglas, Dr. Greg Dukeman, Jim Hays, Ashley Hill, Dr. Young Kim, Robin Pinson, Terri Schmitt, Rob Stough, and Eric Waters. The authors are also grateful for Dr. Bernard Beard for assistance with the statistical calculations. 


\section{References}

${ }^{1}$ Hall, C.E., Lee, C., Jackson, M., West, M., Whorton, M., Brandon, J., Hall, R., Jang, J.W., Bedrossian, N., Compton, J., and Rutherford, C., “Ares I Flight Control System Overview”, 2008 AIAA Guidance, Navigation, and Control Conference, Honolulu, HI.

${ }^{2}$ Jang, J.W., Hall, R., Bedrossian, N., and Hall, C.E., "Ares-I Bending Filter Design Using a Constrained Optimization Approach”, 2008 AIAA Guidance, Navigation, and Control Conference, Honolulu, HI.

${ }^{3}$ Jang, J.W., Van Tassell, C., Bedrossian, N., Hall, C.E., and Spanos, P., "Evaluation of Ares-I Control System Robustness to Uncertain Aerodynamics and Flex Dynamics”, 2008 AIAA Guidance, Navigation, and Control Conference, Honolulu, HI.

${ }^{4}$ Dukeman, G., “Atmospheric Ascent Guidance for Rocket-Powered Launch Vehicles”, AIAA Paper 2002-4559, Proceedings of the AIAA Guidance, Navigation, and Control Conference, Monterey, CA, August 5-8, 2002.

${ }^{5}$ McHenry, R. L., Brand, T. J., Long, A. D., Cockerell, B. F., and Thibodeau III, J. R., "Space Shuttle Ascent Guidance, Navigation and Control,” The Journal of the Astronautical Sciences, Vol. XXVII No. 1, 1979, pp. 1, 38.

${ }^{6}$ Hanson, J.M., Shrader, M.W., and Cruzen, C., "Ascent Guidance Comparisons", The Journal of the Astronautical Sciences, July-Sep., 1995.

${ }^{7}$ Norris, L., Tao, Y.C., Hall, R., Chuang, J., and Whorton, M., “Analysis of Ares I Ascent Navigation Options”, 2008 AIAA Guidance, Navigation, and Control Conference, Honolulu, HI.

${ }^{8}$ Leslie, F.W., and Justus, C.G., "Earth Global Reference Atmospheric Model 2007 (Earth-GRAM07) Applications for the NASA Constellation Program”, $13^{\text {th }}$ Conference on Aviation, Range, and Aerospace Meteorology, New Orleans, LA, Jan. 2008. 